\title{
Sedentary Behavior Research in the Chinese Population: A Systematic Scoping Review
}

\author{
Ran Bao ${ }^{1}{ }^{\oplus}$, Si-Tong Chen ${ }^{2}{ }^{\circledR}$, Yanlei Wang ${ }^{3}$, Jun $\mathrm{Xu}^{1}{ }^{1}$, Lei Wang ${ }^{1}$, Liye Zou ${ }^{4} \mathbb{D}$ and Yujun Cai ${ }^{1, *}$ \\ 1 School of Physical Education and Sport Training, Shanghai University of Sport, Shanghai 200438, China; \\ baoryan1955@gmail.com (R.B.); xujun050396@163.com (J.X.); w12119@163.com (L.W.) \\ 2 Institute for Health and Sport, Victoria University, Melbourne 3000, Australia; sitongchen@szu.edu.cn \\ 3 Harbin Institute of Physical Education, Harbin 150006, China; wyl0789@163.com \\ 4 Exercise and Mental Health Laboratory, Shenzhen Key Laboratory of Affective and Social Cognitive Science, \\ Shenzhen University, Shenzhen 518060, China; LiyeZou123@gmail.com \\ * Correspondence: caiyujun@sus.edu.cn; Tel.: +86-17721399321
}

Received: 3 May 2020; Accepted: 17 May 2020; Published: 20 May 2020

check for updates

\begin{abstract}
Background: The negative effects of sedentary behavior (SB) on public health have been extensively documented. A large number of studies have demonstrated that high prevalence of SB is a critical factor of all-cause mortality. Globally, the frequency of SB research has continued to rise, but little is known about SB in the Chinese population. Therefore, this review was conducted to scope the research situation and to fill the gaps related to the effects of SB in the Chinese population. Methods: Using a scoping review based on York methodology, a comprehensive search of published journal articles and grey literature was carried out through 12 databases. The literature research was conducted by two authors in July 2019, and included journal articles that targeted on the Chinese population were published between 1999 and 2019. The two authors screened the records independently and included those research topics related to SB in the Chinese population. Results: The number of included studies increased from 1 to 29 per year during the analyzed period, during which, a remarkable climb happened from 8 in 2013 to 19 in July 2019. Out of the 1303 screened studies, a total of 162 studies (81 English and 81 Chinese journal articles) met the inclusion criteria in this review. Most of the included studies (66.0\%) reported the overall estimated prevalence of SB, in which, $43.2 \%$ of studies reported the average time of SB, and $40.0 \%$ of studies reported the cutoff point of SB. Besides this, $54.9 \%$ and $23.5 \%$ of studies focused on the outcomes and correlates/determinants of SB, and the proportions of studies based on testing the validation of measurement tools and on interventions were $3.7 \%$ and $4.9 \%$, respectively. Nearly all of the reviewed articles used data from cross-sectional studies $(75.9 \%)$ and longitudinal studies $(13.6 \%)$, while intervention trials are less developed. The majority of the studies (64.8\%) used self-reported surveys, and only 3.7\% studies used device-based measurement tools. Furthermore, $35.8 \%$ of the included studies were focused on children and adolescents, while only a few studies investigated infants/toddlers and older adults. Both female and male were examined in most studies, and non-clinical populations were investigated in the context of SB in a relatively large number of studies. Conclusions: The number of research articles on SB in the Chinese population published per year has increased year by year, indicating a growing interest in this research area. More studies using population subgroup samples are needed, particularly among infants/toddlers, older adults, and clinical populations. To provide stronger evidence of the determinants and outcomes of SB, longitudinal studies using device-based measures of SB are required.
\end{abstract}

Keywords: public health; sedentary behavior; China; review 


\section{Background}

Sedentary behavior (SB) is highly prevalent in populations across the world [1]. However, from the perspective of human biological evolution, the human physiological structure is more suited to exercise [2]. Therefore, reducing SB (e.g., prolonged sitting or screen time) has become a worldwide public concern. SB can be defined as any waking behavior characterized by an energy expenditure of $\leq 1.5$ metabolic equivalents (METs) while in a sitting, reclining, or lying posture [3], which has been recognized as a major risk to public health $[4,5]$. Prolonged SB is an important factor of health in various populations, such as increasing the rate of mortality $[6,7]$, causing cardiovascular diseases $[6,8]$, diabetes mellitus [9,10], metabolic syndrome [11], and cancer [12,13], impairing cognitive function [14], and triggering increased obesity [15]. Despite well-established evidence on detrimental effects of SB on population health, a high prevalence of SB has still been recorded in the literature over the past decades [2]. The alarming prevalence of SB has provoked global actions and initiatives to prevent the global trend. The World Health Organization (WHO) has reported that global mortality due to non-communicable diseases (NCDs) increased from $64 \%$ in 2000 to $71 \%$ in 2016 [16]. Based on the latest evidence, the mortality caused by cardiovascular diseases has increased by $20.9 \%$ over the past few decades [17], and overweight [18] and obesity remain highly prevalent and show an increasing trend in China [19]. Moreover, the burden of chronic NCDs has continued to increase in the past three decades, especially among the older adults in the Chinese population [17].

As the biggest developing and most populous country, China has suffered the burden of excessive SB. Many studies have shown a positive relationship between SB and NCDs [20] in the Chinese population, such as increased obesity [21,22], cardiovascular diseases $[23,24]$, diabetes [25,26], cancer [27], and hypertension [28]. However, the data show that the Chinese population, regardless of gender and age, are increasingly exposed to extended SB [29-31]. For example, an increasing trend was found among Chinese children [32], and 30\% of youths spent more than $3 \mathrm{~h}$ per day engaged in SB [31]. According to the Physical Activity and Fitness in China-The Youth Study (PAFCTYS), a large-population school-based survey [33], over 36.8\% of students spent more than $2 \mathrm{~h}$ per day engaged in SB in 2016 [34], and 34.6\% in 2017 [35]. Additionally, a high prevalence of SB has also been found in adults and older adults [24,30,36,37].

The higher levels of SB in the Chinese population are mainly due to the rapid change of society [38]. Evidence has shown that the built environment is associated with excessive SB [39]. In China, a sharp increase in the urban population has resulted in a shortage of public resources (e.g., insufficient exercise facilities [40]) and an obesogenic environment (e.g., more sitting) [41]. These changes may be the cause of the high prevalence of SB and NCDs in China [38]. On the other hand, the rapid change in the structure of the population is another great problem that China has to cope with, particularly in terms of the subsequent rise in SB. In regard to size, China's aging population is the fourth largest worldwide [42]. In comparison, although China entered an aging society later than Japan, the process of aging is faster and starts earlier for the Chinese population [43]. In addition, social culture may be another reason for the high level of SB. For instance, Chinese youths face more social and cultural pressure related to academic performance $[44,45]$ — the length of time Chinese children and adolescents spend on doing their homework is greater than that of children and adolescents in Canada and the UK [44].

Faced with such concerning public health issues, the Chinese government has issued some initiatives and actions to minimize the health burden and to resolve the related health problems. The recent Healthy China 2030 Blueprint stresses that promoting an active lifestyle in the Chinese population is the biggest health plan action for achieving improved health [46]. Other similar actions for younger people, such as the National Fitness Program (2016-2020) and the Youth Sports Promotion Program (2017), have also established national-level policies for reducing SB among this population, which have been supported by policymakers.

Over the past decade, epidemiological SB research has been on the rise, owing to its detrimental effects. In this field, many previous systematic reviews have examined the prevalence, correlates, and 
health outcomes of SB across different populations. However, those reviews are narrow in nature, focusing on specific domains in the field of SB research, which in turn limits researchers' insights into the populations in some countries. The deficiency may result in an imbalance of SB research across the world. Also, there is no comprehensive review that investigates studies of SB among the Chinese population. Indeed, addressing or preventing the high prevalence of SB in the Chinese population would provide complementary benefits to reduce the global health burden of excessive SB. Hence, our study aims to examine the studies on SB among the Chinese population by using a scoping systematic approach. In turn, this study identifies gaps in the SB research in the Chinese population, and proposes future recommendations and directions for epidemiological SB research and policy practice.

\section{Methods}

\subsection{Search Strategy}

This scoping review was performed based on the York methodology outlined by Arksey and O'Malley [47,48], and according to the Guidance for Conducting Systematic Scoping Reviews [49]. With the aim of identifying research gaps and mapping out the existing literature by examining the extent and nature of said research, this review was conducted as a scoping review. A literature search was conducted to identify relevant published studies about SB in the Chinese population. Before the literature search, we discussed the details about the research question and the search strategy. Then, searches were conducted in 12 electronical databases (WOS, PubMed, EBSCO, Academic Search Premier, SPORTDiscus, MEDLINE Complete, Psychology and Behavioral Sciences Collection, ScienceDirect, ERIC, PsycINFO, SCOPUS, CNKI, and WANGFANG DATA) in July 2019. The definition of sedentary behavior in this review refers to a sitting or leaning posture with an energy consumption less than 1.5 METS during any waking behavior [50]. The search terms were discussed by the authors, and the keywords included "sedentary behavior" or "sitting time" or "screen time." Appendix A shows the detailed search strategies used for each database. The search was modified as needed to meet the different database's search criteria. Additional articles and grey literature documents were identified via a literature search of the reference lists of all of the articles selected in the database search.

\subsection{Study Selection and Inclusion Criteria}

Two authors separately conducted the literature review, and then combined and removed duplicated literature. All records from the literature search were imported into EndNote X9 software. After removing duplicates, the remained records were screened independently by two reviewers in terms of their titles and abstracts (BR and XJ). Any disagreements between the two reviewers were resolved in discussion, and a consensus was reached with a third reviewer (SC).

Studies were included in the present review if they: (1) included any Chinese population in China; (2) conducted research on SB, including any waking screen or sitting behavior characterized by an energy expenditure $\leq 1.5$ metabolic equivalents (METs) in daily life; (3) collected any quantitative data related to SB, including levels, prevalence, correlates, determinants, outcomes, measurement tool or intervention (intervention trials in the Chinese population in China) studies; (4) included any type of SB measure, such as self-reports or device-based measures; and (5) published in either a English or Chinese language peer-reviewed journal article. Studies were excluded if they: (1) targeted non-Chinese populations and Chinese people outside of China; (2) the main outcome(s) focused on sports/exercise/skill performance or physical therapy; or (3) were published as a literature review, commentary, conference abstract, or editorial. 


\subsection{Data Extraction}

The data of the included studies were compiled according to the following data extraction method, and descriptive analysis and reporting frequency counts were performed. The purpose of the review was discussed, taking into account the impact on research, policy, and practice.

The following data were extracted from the included studies: (1) administrative information, including author names, publication year, and title; (2) the study method, including the study design, survey method, sample size, and sampling method; (3) characteristics of the study sample, including sex, age, municipality (rural/urban), region, and other specific characteristics of the participants; (4) the study measure, including the type of SB measure, the device or questionnaire name, the type of SB (such as sitting time, screen time, and transport), the validity of measures, and the intervention type); and (5) the study objective, including determinants/correlates, and outcomes topics categorized according to previous studies [15,51,52]. Definitions of these topics are as followed: (1) Socio-demographic includes age, sex, place of residence, religion, educational level, membership in organizations and social groups; (2) genetic includes gene-related indicators; (3) health behaviors/lifestyle/knowledge include physical activity, life habits, health knowledge; (4) general health includes overweight/obesity, sleep quality, fat mass, and other health indexes; (5) diseases mean chronic noncommunicable diseases, such as, cancer, diabetes, hypertension, cardiovascular; (6) skills/abilities/fitness include sport skill, body abilities and fitness; (7) psychological factors include mental health, cognitive ability and others; (8) social and culture include social device or feeling support; (9) built/natural environment includes those built or natural environment affecting SB; (10) academic performance includes academic burden or pressure. The detailed data extraction table for the studies used in this review is available in Additional file 1.

\section{Results}

The literature search and selection processes can be found in Figure 1. In total, 175 Chinese and 1128 English journal articles were identified through the database search, of which 170 Chinese and 740 English records remained after removing duplicates. Following title and abstract scanning, 78 Chinese and 131 English potentially relevant articles were retained. According to the inclusion and exclusion criteria, 76 Chinese and 79 English full-text records were included, and seven more articles were added from reading those full-text records. Finally, a total of 162 studies were included for this review [20-30,32,34-37,44,53-197].

\subsection{Description for Trends of the Included Studies}

All articles included in this review were published between 1999 and 2019, the details of which are shown in Figure 2. As can be seen, the number of papers published per year has witnessed an increasing trend over the analyzed period. The number of SB-based articles focusing specifically on the Chinese population increased steadily from 1999 to 2013, then climbed sharply during the following 5 years, with a peak at 29 in 2018. Although the literature search was conducted in July of 2019, the number of SB-related studies in 2019 was still high.

\subsection{Characteristics of the Study Design and the Sample}

The characteristics of the study design and the sample are outlined in Table 1. Of the studies included in this review, most of the quantitative studies were cross-sectional surveys $(75.9 \%)$ aimed at detecting the relationship between SB and its correlates or outcomes. However, few studies were of a longitudinal design (13.6\%), and only $4.9 \%, 3.1 \%$, and $2.5 \%$ were intervention trials $[54,103,118,136-138,194,195]$, measurement studies $[64,75,108,119,125]$, or case-control studies $[21,78,84,113]$, respectively. The sample sizes of the included studies ranged from 26 to 1,048,594, and $20.4 \%$ of the studies were conducted using nationally representative samples. Of these studies, $63.6 \%$ solely conducted secondary data analyses of national surveys, such as the Physical Activity and Fitness in China-The Youth Study, the China Health and Nutrition Surveys (CHNS), the China Education Panel Survey-Junior High 
Cohorts study, the 2014 Physical Fitness and Health Index of Child and Adolescents (PFHICA) study, and the Chinese Youth Risk Behavior Survey. Most studies (45.1\%) were conducted in urban regions, followed by $27.2 \%$ in both urban and rural regions, and only $3.1 \%$ in rural regions, the details of which are shown in Table 1.
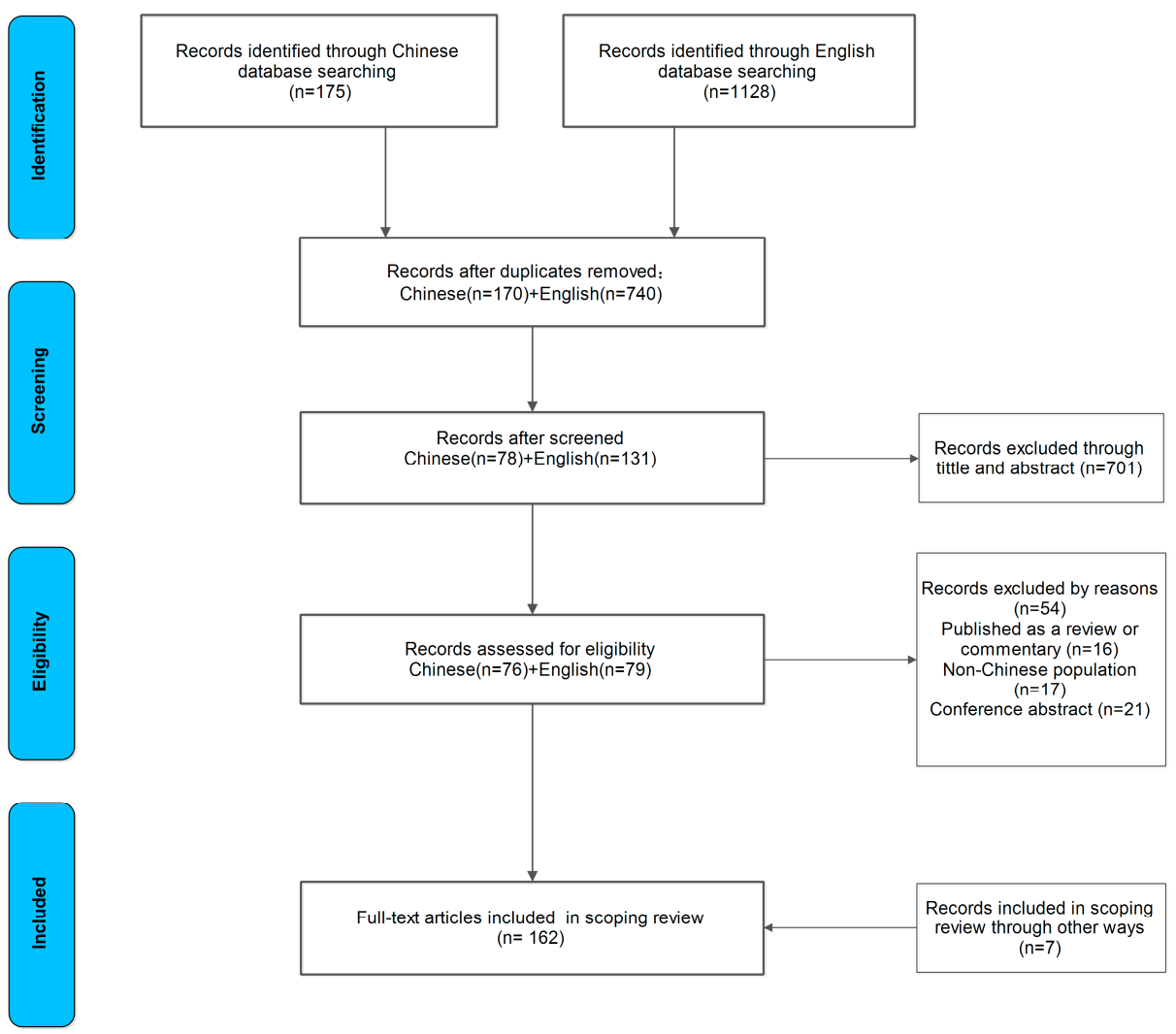

Figure 1. Flow diagram of the study selection process.

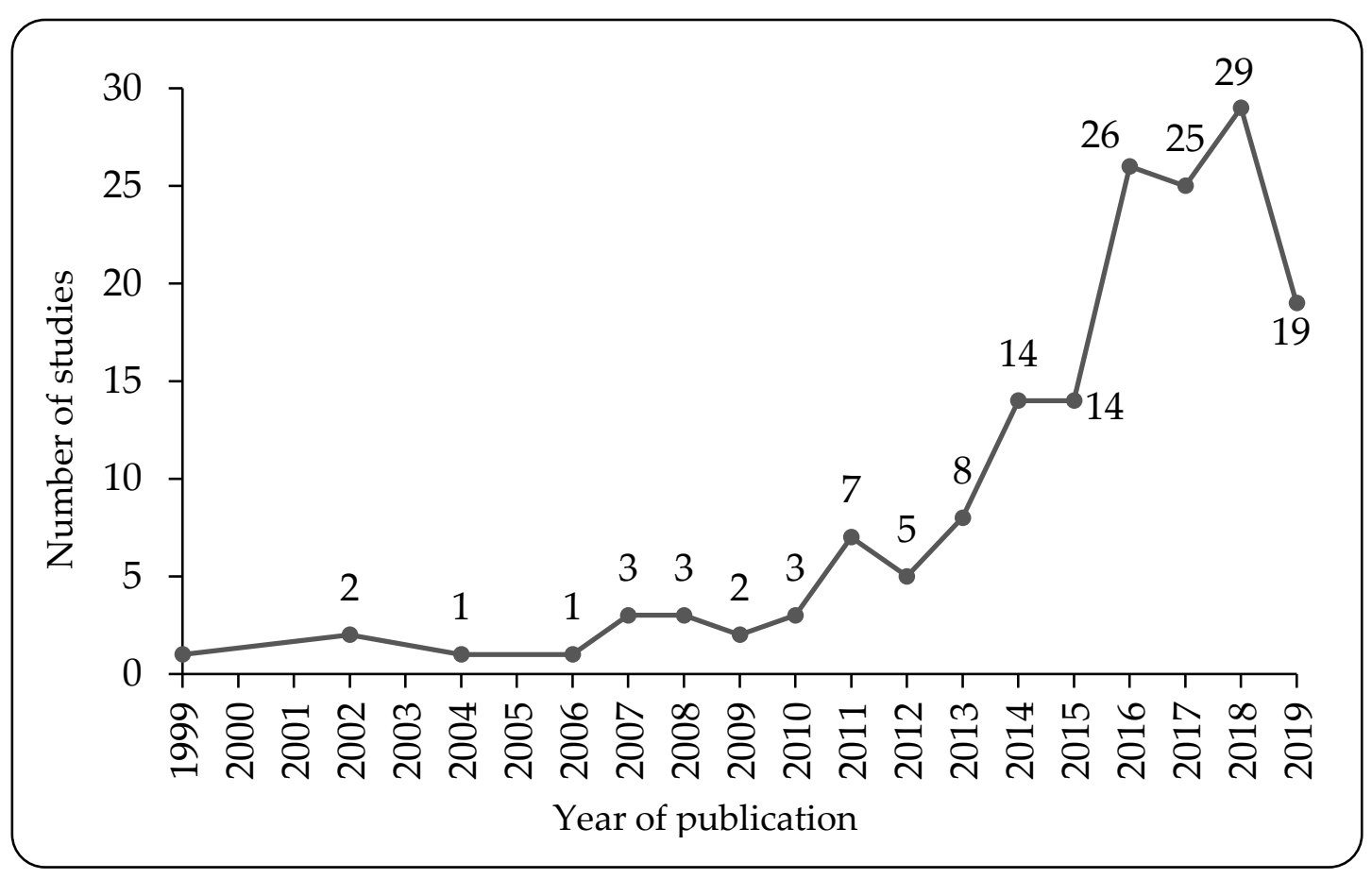

Figure 2. The number of studies on SB published per year (time to July 2019). 
Table 1. Characteristics of the study design and sample.

\begin{tabular}{ccc}
\hline Study Design & Number & Proportion \\
\hline Cross-sectional studies & 123 & $75.9 \%$ \\
Longitudinal studies & 22 & $13.6 \%$ \\
Intervention trials & 8 & $4.9 \%$ \\
Measurement studies & 5 & $3.1 \%$ \\
Case-control studies & 4 & $2.5 \%$ \\
National surveys (secondary data analysis) & $33(21)$ & $20.4 \%(63.6 \%)$ \\
\hline Sample gender & & \\
Female and male & 141 & $87.0 \%$ \\
Female & 9 & $5.6 \%$ \\
Male & 4 & $2.5 \%$ \\
Not report & 8 & $4.9 \%$ \\
\hline Population subgroup & & \\
Only Infants/toddlers & 5 & $3.1 \%$ \\
Only Children and adolescents & 58 & $35.8 \%$ \\
Only Adults & 18 & $11.1 \%$ \\
Only Older adults & 3 & $1.9 \%$ \\
\hline Sample region & & \\
Urban and rural & 44 & $27.2 \%$ \\
Only urban & 73 & $45.1 \%$ \\
Only rural & 5 & $3.1 \%$ \\
\hline
\end{tabular}

Participants of both genders were included in $87.0 \%$ of the studies. Studies of females only $(5.6 \%)$ were more common than studies of males only (2.5\%). Only children and adolescents (7-17 years) were the most frequently investigated age group $(35.8 \%)$, followed by adults (18-64 years; $11.1 \%$ ), infants/toddlers ( $3-6$ years; $3.1 \%)$, and older adults $(\geq 65 ; 1.9 \%)$. The large majority of the studies were conducted in non-clinical populations ( $88.9 \%)$, of which, $46.9 \%$ were conducted among primary school, secondary school, high school, and university students. The remaining studies targeted the general population $(35.8 \%)$, patients $(7.4 \%)$, the occupational population $(3.1 \%)$, or others $(6.2 \%)$, the details of which are shown in Table 2.

\subsection{Measurement of Sedentary Behavior}

The details of the data collection methods are shown in Figure 3. The majority of the included studies (64.8\%) used questionnaire-based self-report measures; $49.4 \%$ of the studies did not specify the type of questionnaire; International Physical Activity Questionnaires (IPAQ) and accelerometers were used in $14(8.6 \%)$ and seven (4.3\%) studies, respectively; the Youth Risk Behavior Surveillance System (YRBS) questionnaire and the Health Behavior School-aged Children (HBSC) questionnaire were used in four and two studies, respectively; and $27.8 \%$ of the included studies reported the validity of the questionnaire(s) used. Furthermore, interviews and mix methods (the use two or more methods, e.g., a questionnaire and an accelerometer) were used in 16 studies (9.9\%); a proxy report was used in 10 studies $(6.2 \%)$, including a parent/guardian or teacher proxy; nine studies $(5.6 \%)$ used other methods (e.g., the inquiry method) or did not report a method; and only six studies (3.7\%) used device-based measures, including an accelerometer or a pedometer. 
Table 2. The population groups included in the studies on SB research of Chinese population.

\begin{tabular}{cc}
\hline Population Groups & No. of Studies \\
\hline Non-clinical populations & \\
Students & 76 \\
General (no specific characteristics) & 58 \\
Occupation-specific populations & 5 \\
Health-care students & 1 \\
Obese/overweight & 1 \\
Multiple populations groups & 1 \\
High risks of chronic diseases population & 1 \\
Religious groups & 1 \\
Total & 144 \\
\hline
\end{tabular}

\begin{tabular}{cc}
\hline Clinical populations (general characteristic) & \\
Chronic/diabetes/hypertension & 5 \\
Pregnant and postpartum women & 3 \\
Cardiovascular & 2 \\
Patients (no specific characteristics) & 1 \\
Acute coronary syndromes & 1 \\
Epithelial ovarian cancer & 1 \\
Colorectal cancer & 1 \\
Esophageal squamous cell carcinoma & 1 \\
Male infertility & 1 \\
Total & 16 \\
Not reported & 2 \\
\hline TOTAL & 162 \\
\hline
\end{tabular}

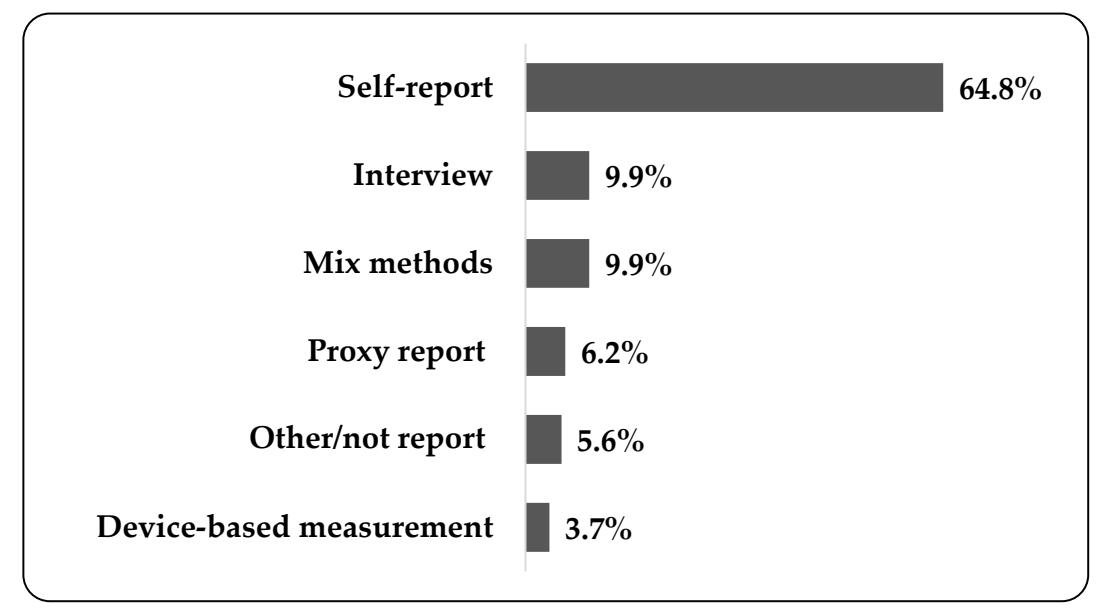

Figure 3. The proportion of data collection methods of SB (mixed method: the use two or more methods, e.g., a questionnaire and an accelerometer).

\subsection{Categorizations of the Study Topics}

In the studies included in this review, a substantial proportion (66.0\%) reported the estimated prevalence of SB. Specifically, $28.4 \%$ focused on both screen time and sitting time; $56.1 \%$ reported screen time, including TV viewing, computer use, videogames, and internet/social networking; and $40.1 \%$ concentrated on sitting time, including reading, writing, drawing, homework, and playing musical instruments. However, only five studies reported transport-related SB. Moreover, in these prevalence studies, $43.2 \%$ reported the duration of SB, the details of which are outlined in Figure 4 . Specifically, 32.1\% of studies demonstrated that participants spent between 2 to $4 \mathrm{~h}$ per day engaged in SB, while duration of $4-6 \mathrm{~h}$ and over $6 \mathrm{~h}$ per day were reported in $22.6 \%$ and $28.3 \%$ of the studies, respectively. Most studies reported that youths spent more than $2 \mathrm{~h}$ per day, varying from 1.55 to 
$8.7 \mathrm{~h}$ per day engaged in SB, while $41.4 \%$ of studies reported that youths spent more than $6 \mathrm{~h}$ per day engaged in SB. In terms of adults and older adults, $10.7 \%$ and $9.5 \%$ of studies reported that more than $6 \mathrm{~h}$ per day was spent engaged in SB, respectively. In addition, $40.0 \%$ of the studies reported the cutoff points to detect the prevalence of SB, the details of which are outlined in Figure 5. Specifically, $62.0 \%$ of the studies reported the proportion of participants who spent more than $2 \mathrm{~h}$ per day engaged in SB, while $6.0 \%$ and $10.0 \%$ reported more than $4 \mathrm{~h}$ and $6 \mathrm{~h}$, respectively. The different prevalence results are related to the diversity of the cutoff point; $70.3 \%$ of the studies that used cutoff points ( $\geq 2 \mathrm{~h}$ per day) reported the percentage of youth in sedentariness, ranging from $4.7 \%$ to $80.0 \%$. Meanwhile, in terms of adults and older adults, with the proportion reporting SB ranging from $15.0 \%$ to $93.5 \%$.

Details of the correlates/determinants and study outcomes (e.g., genetic, health variables) of SB are outlined in Table 3. Of the included studies, the general aims focused on the outcomes of SB $(54.9 \%)$. The main aims of the outcome studies were focused on general health $(39.4 \%)$, such as obesity, overweight, sleep quality and others; disease (35.4\%), including chronic diseases, morbidity, diabetes, cancer and others; psychological factors $(11.1 \%)$, such as, depression, anxiety symptoms, cognitive ability, and psychiatric symptoms. Genetical factors, health behaviors, and skills/abilities/fitness were seldom identified in the Chinese population.

Table 3. Number of studies investigating the correlates and outcomes of SB.

\begin{tabular}{ccccc}
\hline \multirow{2}{*}{ Categories } & \multicolumn{2}{c}{ Correlates } & \multicolumn{2}{c}{ Outcomes } \\
\cline { 2 - 5 } & No. of Studies & $\%$ & No. of Studies & $\%$ \\
\hline (1) Socio-demographic & 27 & $34.6 \%$ & - & - \\
(2) Genetic & - & - & 1 & $1.0 \%$ \\
(3) Health & 14 & $17.9 \%$ & 5 & $5.1 \%$ \\
behaviors/lifestyle/knowledge & 1 & $1.3 \%$ & 39 & $39.4 \%$ \\
(4) General health & 3 & $3.8 \%$ & 35 & $35.4 \%$ \\
(5) Disease & 2 & $2.6 \%$ & 8 & $8.1 \%$ \\
(6) Skills/abilities/fitness & 3 & $3.8 \%$ & 11 & $11.1 \%$ \\
(7) Psychological factors & 14 & $17.9 \%$ & - & - \\
(8) Social and culture & 10 & $12.8 \%$ & - & - \\
(9) Built/natural environment & 4 & $5.1 \%$ & - & - \\
(10) Academic performance & $78(38)$ & $100 \%$ & $99(89)$ & $100 \%$ \\
Total * & &
\end{tabular}

Note: ${ }^{*}$ Multiple correlates and/or outcomes were investigated in some studies; hence, the sum of the totals is greater than the total number of these studies.

In total, the proportion of studies concentrated on the correlates/determinants of SB was $24.1 \%$. Among these studies, the socio-demographic factors (34.6\%) were the most common correlates, such as age, gender, and education level, followed by health behavior/lifestyle/knowledge factors $(17.9 \%)$, such as physical activity, diet, and health knowledge; $17.9 \%$ of the studies concentrated on social and cultural factors, such as social support, parents' rules, and parental modeling, sport organization; and $12.8 \%$ of the studies focused on the built/natural environment, such as physical activity facilities, the weather, safety of and/or access to public transport. A limited number of studies (11.5\%) investigated psychological (e.g., attitude, self-efficacy), academic performance, skills/abilities/fitness factors.

Moreover, few studies targeted the validation of an SB-related measurement tool (3.7\%) or of intervention trials (3.8\%). Only two of them tested the validation of the Health Behavior in School-aged Children (HBSC) survey questionnaire and the long-term and short-term recall of occupational sitting time questionnaire, and one focused on the Sense Wear Mini Armband. 


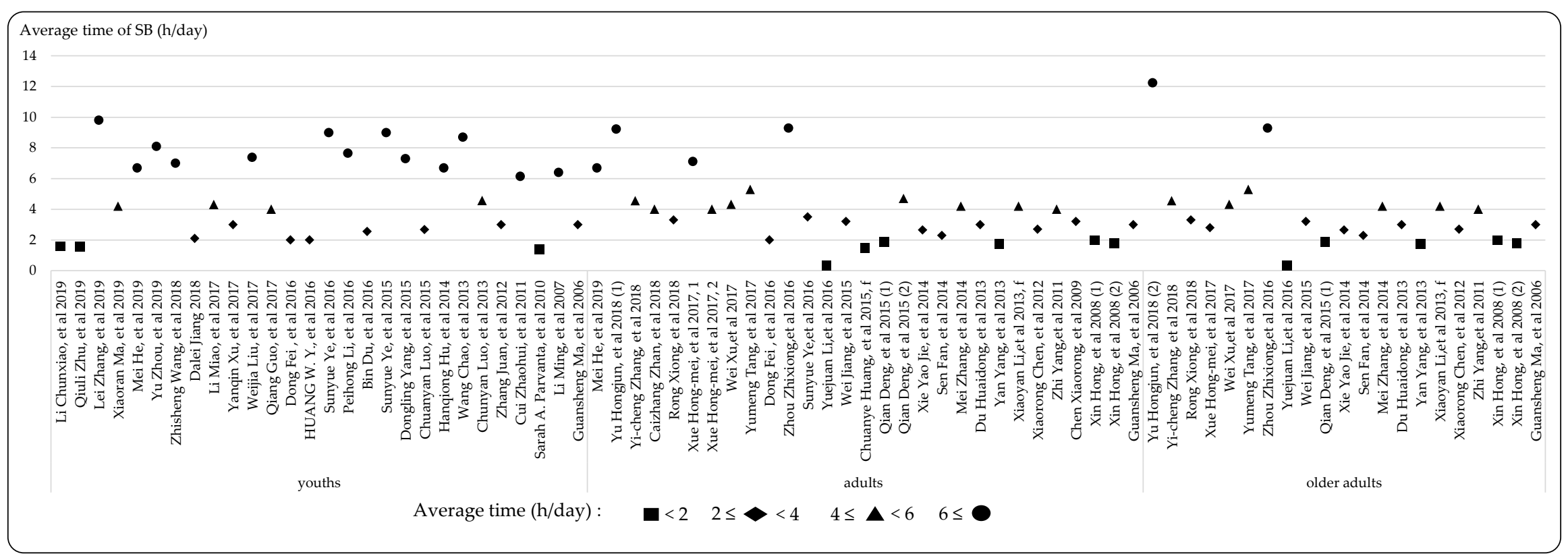

Figure 4. The average duration (h/day) engaged in SB (in the form [198]) (abbreviations: $\mathrm{m}=$ male; $\mathrm{f}=$ female; youths $<18$ years; 18 years $\leq$ adults $<65$ years; older adult $\geq 65$ years; Xue Hong-Mei, et al. 2017, $1=20-40$ years [196]; Xue Hong-Mei, et al. 2017, 2 = 41-55 years [196]). 


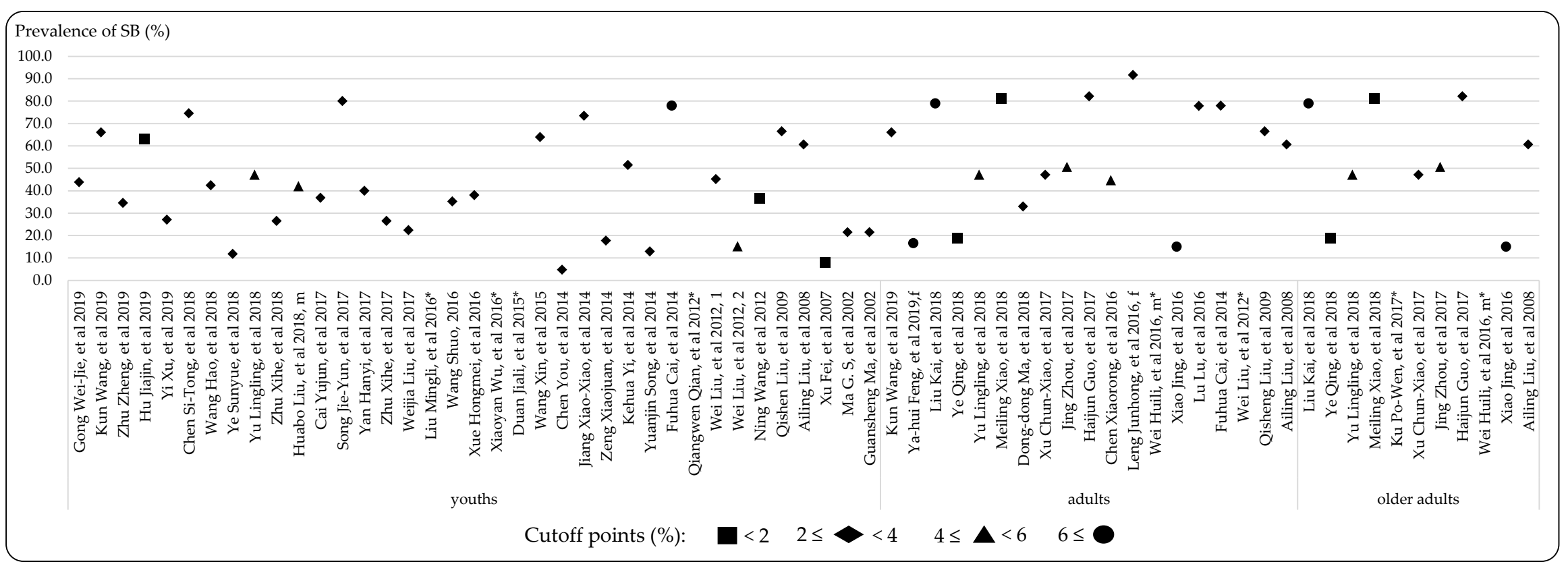

Figure 5. The prevalence (\%) of SB of included studies reporting the cutoff points (in the form [198]) (abbreviations: * No information on overall prevalence available; $\mathrm{m}=$ male; $\mathrm{f}=$ female; youths $<18$ years; 18 years $\leq$ adults $<65$ years; older adult $\geq 65$ years; Wei Liu, et al. 2012, 1 = screen time [177]; Wei Liu, et al. 2012, $2=$ sitting time [177]). 


\section{Discussion}

This scoping review examined and summarized the evidence of SB research in the Chinese population. Firstly, literature review indicated that the number of SB research in the Chinese populations increased rapidly over the past two decades, and $71 \%$ of the included studies were published over the past five years, which is consistent with the figures reported by other countries [52,199]. This increasing trend demonstrates that SB has become a popular research topic in China. Secondly, the included studies reported that Chinese population spent a large amount of time on SB. Moreover, socio-demographic, health behaviors/lifestyle/knowledge, cultural/social, and built/ natural environment factors were the main aspects of correlates of SB, and general health and diseases were the main outcome topics of the relevant studies in this review. Thirdly, the majority of the included studies targeted children and adolescents using cross-sectional design and self-report questionnaires. In addition, most of the empirical research studies investigated the specific types of SB, including screen time (such as watching TV, using computer/internet, playing electronical games) and sitting time (such as doing homework, playing musical instruments, reading/writing). Only a limited number of studies focused on transport-related SB.

\subsection{SB Study Design and Measurement}

The majority of the studies in this review were cross-sectional design and used self-report measures, which is consistent with previous similar reviews [200-202]. Time and cost burden may be a barrier of conducting longitudinal and interventional studies in China. However, cross-sectional studies cannot provide the cause-and-effect association between exposures (i.e., independent variables) and outcomes (i.e., dependent variables). More longitudinal studies are encouraged to conduct in the Chinese population. In addition, several studies included in this review were based on national surveys, such as the Physical Activity and Fitness in China-The Youth Study (PAFCTYS), the China Health and Nutrition Surveys (CHNS), and the China Education Panel Survey-Junior High Cohorts study. Notably, few studies targeted younger children (e.g., 3-6 years) and older adults (e.g., $\geq 65$ years). To improve the generalizability of the findings from SB epidemiolocal studies, more studies should be encouraged to focus on special populations in the future.

In terms of the measurement of SB in this review, most of the included studies used self-report methods to collect data. Although self-reported measures (e.g., questionnaires) are susceptible to low response rates, misclassifications, and difficulty in determining the direction of the effects between variables [203], this method is still widely used in SB research at large-scale level [204,205]. Although questionnaires were used by the studies included in this review, such as the IPAQ, the Children's Leisure Activities Study Survey questionnaire-Chinese version, and the Youth Risk Behavior Survey System (YRBSS) questionnaire, only half of these studies reported the validity. In order to ensure the reliability and validity of data, the use of questionnaires with accepted reliability and validity is mandatory. In contrast, device-based measures (e.g., accelerometers, pedometers) can provide more accurate data; however, such measures only mechanically record moving or acceleration information of the wearing section of body, and fail to identify specific body postures and types of SB (e.g., whether carrying weight or not, standing, or sitting) [206]. Although device-based measurements have many limitations when evaluating a particular type of SB, compared to different modified versions of the questionnaire, it is easier to obtain validity in international comparisons [204]. Currently, posture monitors such as activPAL have become a reliable and valid measure in recording SB patterns $[207,208]$. One study even suggests that combining movement monitors (accelerometers) with physiological sensors (heat rate monitors) might be a potential method to improve the accuracy of SB measurement [209]. Therefore, for a better understanding, there is a need for more studies to use valid questionnaires and device-based measures to collect SB data in the Chinese population. In addition, the majority of the included studies focused on screen time, such as TV viewing, computer use, videogames, and internet/social networking, but failed to distinguish between the different outcomes of screen time, traffic SB, and recreational SB. Furthermore, evidence has demonstrated that different types of 
SB generate differentiated health risks. For example, SB in regard to television viewing is related to cardiovascular disease, but the same results are not found when using a computer [210]. Therefore, investigating the effects of different types of $\mathrm{SB}$ on public health can provide a more effective mechanism for reducing SB itself.

\subsection{SB Sub-Populations}

Youths and adults were the most commonly studied sub-populations, followed by mixed groups (more than two age groups)/not reported, and then adults (18-64 years); few studies targeted infants/toddlers or older adults. This is in contrast to a study in Thailand, which indicated that adults (18-59) are the most commonly studied age group [52]. The main reason might be the convenience in measuring and detecting the detrimental effects (e.g., chronic diseases) of SB in middle-aged adults. Besides, another reason may be that the Chinese government is greatly concerning about youth health. Due to the severe health problems of children and adolescents [211], the Chinese government has been spending a lot of manpower and resources to overcome this public health issue. Obviously, the orientation of policy has affected on the popularity of choosing children and adolescents as targets. In addition, the difficulties related to conducting surveys with infants/toddlers and older adults may also partially explain why most Chinese SB studies focus on younger age groups. Therefore, more research into these age groups is required in the future.

Moreover, the majority of the included studies concentrated on student and general populations, but few focused on the occupation-specific population, the obese/overweight population, pregnant and postpartum women, and religious and other populations in China. Recently, studies have revealed that maternal recreational exercise during pregnancy is related to 7-year-old children's body mass index (BMI) scores and their risk of becoming overweight [212]; SB during pregnancy is also reported to generate a negative impact on pregnant women's health [213]. However, whether SB during pregnancy really does have negative impacts on the health of women and infants requires more evidence. Nowadays, insufficient awareness of the health risks associated with SB has resulted in a rapid increase in the prevalence of obesity and chronic diseases in Chinese society, which has resulted in concerning medical burdens for society. The death rate as a result of chronic diseases in middle-aged people is higher in China than in various high-income countries [214]. As the rate of the aging population, of urbanization, and of social and economic reforms continues to progress, the prevalence of chronic diseases in China will continue to rise. Therefore, researchers should pay more attention to $\mathrm{SB}$ of special populations in China.

\subsection{SB Study Topics}

Notably, a high prevalence of sedentariness was not only found in Chinese youths, but also in adults and older adults. However, due to the lack of consistent standards, it is hard to extract the overall estimated prevalence of SB in population subgroups. Most of the prevalence studies concentrated on screen time and sitting time, while a limited number of studies focused on transport-related SB. However, SB related to transport has been widely examined in other countries, the results of which show differences between urban and rural environments. Furthermore, one study has indicated that SB may be replaced by standing or slow movement in urban transport settings [215]. Therefore, further studies should consider refining transport-related SB research. Moreover, studies have shown that the effects of different volumes or types of SB may result in a variety of health outcomes [216]. In this review, although most of the included studies targeted the prevalence of SB, few studies focused on the prevalence of SB within different locations and of types. Additionally, it was observed that the cutoff points of SB vary from 2 to $9 \mathrm{~h}$ per day, although most studies used $2 \mathrm{~h}$ per day to assess the estimated prevalence of screen time for the Chinese population in this review. The average time youths spent on SB was indicated to be more than $6 \mathrm{~h}$ per day. Furthermore, different amounts of SB cause a diversity of health risks in different age groups, and a lack of risk criteria related to SB for specific populations may make it difficult to accurately predict health risks of said population groups [217]. 
The research topics included in this review encompassed multiple dimensions, which is consistent with current SB research around the world [218-221]. The studies included in this review mostly concentrated on the outcomes of $\mathrm{SB}$, while few studies focused on the determinants/correlates. General health problems (e.g., obesity, overweight, sleep quality) and diseases (e.g., cardiovascular, metabolic, and mental diseases) were the main topics of the outcomes in this review. Due to insufficient evidence, it is hard to determine whether other diseases such as cancer, type 2 diabetes, and musculoskeletal disorders also have a certain relationship with SB [15]. It is worth noting that the prevalence of diabetes and cancer has continuously increased in recent years in China [222,223], and a quarter of diabetes patients around the world were located in China [224]. More studies are encouraged to focus on these diseases, especially in adults and the aging population in China. Meanwhile, a limited number of studies have concentrated on genetical factors, health behaviors, or skills/abilities/fitness factors. For example, it has been revealed that screen (TV viewing) and sitting time is related to unhealthy behavior (e.g., physical inactivity, diet), including aggression in children and smoking or alcohol consumption in adults [15]. Another review indicated that SB is inversely associated with physically aggressive behavior in younger children, and most studies identified this relationship via TV viewing time [225]. Recently, issues related to violence in children have frequently occurred in China; however, few of the studies focused on the outcome of aggression in this review. Therefore, research into whether sitting time or other types of SB are related to other risk behaviors in Chinese youths is still required. In this review, a few studies focused on academic performance as a correlate, but none identified the effects of SB on academic performance in China. For instance, these studies showed that spending a long time engaged in SB is associated with decreased academic performance [226,227]; however, the relationship between spending more time on homework [44] and academic performance (e.g., cognition performance, grade point, memory, attention) [226] is not clear in Chinese youths. In future research, the relationships should be clearly clarified.

In this review, the determinants/correlates of the Chinese population can be divided into several main categories, including individual, social, and environmental factors [52]. Such categories include socio-demographic, health behaviors/lifestyle/knowledge, skills/abilities/fitness, psychological, academic performance, social and cultural, built/natural environment, which is consistent with the outcomes of two determinant studies [201,228]. However, the majority of included studies focused on socio-demographic (e.g., age, gender, education level), health behavior (e.g., exercise), and social/culture (e.g., social support) factors, and few studies focused on built environment, psychology, academic performance. In terms of academic performance, high social and cultural pressure may be an important explanation of the high prevalence of SB in Chinese youths. For example, evidence has shown that Chinese children spend more time than children from other countries (e.g., Canada, UK) on homework [44]; this relationship has been widely examined in other countries, the outcomes of which highlight the negative impact of SB on academic performance among children and adolescents [227]. In this review, however, only four studies focused on the relationship between academic performance and SB on Chinese youths. Further studies need to focus on this field in order to elucidate the relationship between academic performance and SB in China. Moreover, SB-related policies are undeveloped in China, with limited policies focusing on reducing SB. Previously, the orientation of policies to Chinese research has been discussed in this review, therefore, effective policies should be encouraged to reduce SB in the Chinese population. In addition, few of the studies included in this review concentrated on the built environment, and of those that did, most of them targeted children and adolescents, which is consistent with a different review [39]. Nowadays, changes of built environment (e.g., insufficient exercise facilities and obesogenic environment) and fast process of aging have been main challenges for limiting SB in the Chinese population. Further studies focusing on built environments should be encouraged in China, especially in adults and the elderly.

However, only eight studies were intervention trials in this review. This finding is consistent with several studies, which showed interventions for SB developed in Europe, the USA, and Australia, but not in China $[229,230]$. This may be related to limited evidence regarding the correlates for 
population subgroups. Most SB research are at individual level, but a single dimension is inefficient for addressing SB [231]. The socio-ecological model highlights the importance of multi-level factors in terms of addressing public health issues; thus, there is a dynamic relationship between the individual level, the intrapersonal level (i.e., social support [232]), the organization level, the community level, and the policy level [221]. In order to develop more effective behaviors reduction interventions, further studies need to concentrate on the dynamic relationship between these factors of SB in the Chinese population. In this way, more feasible and effective intervention programs can be conducted on the Chinese population based on these correlates [233].

\subsection{Strengths and Limitations}

The advantage of this review lies in its use of systematic search and selection strategies to identify relevant studies. Furthermore, a large number of sedentary behavioral studies on the Chinese population were retrieved through 12 English or Chinese electronical databases. Second, the determinants/correlates and outcomes were categorized to facilitate the development of follow-up research. However, there are some limitations to this scoping review. While it is desirable to include as many studies as possible that meet the inclusion criteria, there may be omissions due to the availability of the study and the comprehensive nature of the database. In addition, due to the limit of heterogeneity in SB (e.g., different types and measures of $\mathrm{SB}$ ), this review focused on the description of the basic characteristics. In the future, the epidemiological characteristics of SB in the Chinese context should be summarized for different ages, different groups of people, and different study topics.

\subsection{Recommendations for Future Research}

Based on the aforementioned analysis, several suggestions can be made for directing future research conducted in China. Firstly, based on the obvious policy orientation of SB research in China, as well as the high prevalence of SB and chronic disease rejuvenation, future research should focus on the correlates/determinates of SB. Secondly, future research should combine the advantages of both self-report and device-based tools to improve the accuracy of SB measurement. Meanwhile, more longitudinal studies should be designed to detect the cause-and-effect relationship of SB. Future studies in China could also be strengthened by using validated device-based and self-report measures of SB. Additionally, for a better understanding of the determinants and outcomes of SB in China, future studies should aim to use longitudinal study designs. Thirdly, due to the differences of the determinates and outcomes between population subgroups, it might be useful to concentrate on specific population subgroups, such as infants/toddlers, occupation-specific population, older adults, or clinical populations. Finally, socio-demographic factors were the main focus in the current research in China, and more research is needed on academic performance, built/natural environment, psychology, and social/culture factors relevant to SB.

\section{Conclusions}

In the past decade, SB research has shown a spurt of development. The included studies in this review indicated the high prevalence and gaps of SB research in the Chinese population. However, SB research still has many limitations, such as the methodology used, research topics, and research populations, all of which hinder the healthy development of this research area in China. In further research, more studies should be conducted in the Chinese population subgroups, especially focused on developing more efficient strategies to reduce SB.

Author Contributions: R.B., S.-T.C. and Y.C. conceived the idea for this review. R.B., S.-T.C. and L.W. conducted the literature reviewing. J.X. participated in the work of literature screening. R.B. and S.-T.C. interpreted the results, wrote the final report and they are responsible for the final content of this paper. Y.W. and L.Z. provide important role of improving the manuscript. Ethics approval and consent to participate. All authors have read and agreed to the published version of the manuscript. 
Funding: This study was supported by Shanghai Key Lab of Human Performance (Shanghai University of sport) (NO. 11DZ2261100).

Acknowledgments: None.

Conflicts of Interest: The authors declare no competing interests.

Availability of Data and Materials: The summary of reviewed articles is available in Tables, Figures, and Additional files.

\section{Appendix A}

Search terms used in each database consulted

(1) web of science $=\left(\mathrm{TI}=\left(\right.\right.$ 'sedentary* behavior $^{* \prime} \mathrm{OR}$ 'sedentary* behavior*' OR sitting OR 'watching TV' OR 'TV watching' OR 'TV viewing' OR Television OR 'video watching' OR 'watching video' OR 'computer use' OR 'internet use 'OR 'screen time') AND TI = (China OR Chinese $)=329$ ).

(2) PubMed = (('sedentary* behavior"' [Title] OR 'sedentary* behavior*' [Title] OR sitting [Title] OR 'watching TV' [Title] OR 'TV watching' [Title] OR 'TV viewing' [Title] OR Television [Title] OR 'video watching' [Title] OR 'watching video' [Title] OR 'computer use' [Title] OR 'internet use' OR 'screen time' [Title])) AND (China OR Chinese [Title/Abstract]) $=82$.

(3) EBSCO Academic Search Premier = (TI('sedentary behavior*' OR 'sedentary behavior*' OR sitting OR 'watching TV' OR 'TV watching' OR 'TV viewing' OR Television OR 'video watching' OR 'watching video' OR 'computer use' OR 'internet use' OR 'screen* time') AND SU (China or Chinese) = 281).

(4) EBSCO SPORTDiscus = (TI('sedentary behavior ${ }^{* \prime}$ OR 'sedentary behavior*' OR 'sitting time' OR 'watching TV' OR 'TV watching' OR 'TV viewing' OR Television OR 'video watching' OR 'watching video' OR 'computer use' OR 'internet use' OR 'screen* time') AND SU (China or Chinese) = 20).

(5) EBSCO MEDLINE Complete = (TI('sedentary behavior ${ }^{* \prime}$ OR 'sedentary behavior*' OR 'sitting time' OR 'watching TV' OR 'TV watching' OR 'TV viewing' OR Television OR 'video watching' OR 'watching video' OR 'computer use' OR 'internet use' OR 'screen* time') AND SU (China or Chinese) = 118).

(6) Psychology and Behavioral Sciences Collection $=\left(\mathrm{TI}\right.$ ('sedentary behavior" ${ }^{* \prime}$ OR 'sedentary behavior*' OR 'sitting time' OR 'watching TV' OR 'TV watching' OR 'TV viewing' OR Television OR 'video watching' OR 'watching video' OR 'computer use' OR 'internet use' OR 'screen* time') AND SU (China or Chinese) $=23$ ).

(7) ScienceDirect $=\left(\mathrm{TI}\left(\right.\right.$ 'sedentary behavior*' OR 'sedentary behavior" ${ }^{*} \mathrm{OR}$ 'sitting time' OR 'watching TV' OR 'TV watching' OR 'TV viewing' OR Television OR 'video watching' OR 'watching video' OR 'computer use' OR 'internet use' OR 'screen* time') AND SU (China or Chinese) = 41).

(8) ERIC = (TI('sedentary behavior*' OR 'sedentary behavior" OR 'sitting time' OR 'watching TV' OR 'TV watching' OR 'TV viewing' OR Television OR 'video watching' OR 'watching video' OR 'computer use' OR 'internet use' OR 'screen* time') AND SU (China or Chinese) = 36).

(9) PsycINFO = TI('sedentary behavior" ${ }^{* \prime}$ OR 'sedentary behavior*' OR 'sitting time' OR 'watching TV' OR 'TV watching' OR 'TV viewing' OR Television OR 'video watching' OR 'watching video' OR 'computer use' OR 'internet use' OR 'screen* time') AND SU (China or Chinese) = 95).

(10) Scopus = (1TTITLE (sedentary behavior* OR sedentary behavior*) AND (China OR Chinese) (LIMIT-TO (AFFILCOUNTRY, “China”)) AND (LIMIT-TO (LANGUAGE, “English”)) =55; (2) TITLE ('sitting AND time') AND (China OR Chinese) AND (LIMIT-TO (AFFILCOUNTRY, "China")) AND (LIMIT-TO (LANGUAGE, “English")) =11; (3)TITLE (watching AND tv' OR 'tv AND watching') AND (China OR Chinese) AND (LIMIT-TO (AFFILCOUNTRY, "China”) OR LIMIT-TO (AFFILCOUNTRY, “Taiwan")) AND (LIMIT-TO (LANGUAGE, "English")) =11; TITLE ('video AND watching' OR 'watching AND video') AND (China OR Chinese) AND (LIMIT-TO (AFFILCOUNTRY, "China") OR LIMIT-TO (AFFILCOUNTRY, “Hong Kong”)) AND (LIMIT-TO (LANGUAGE, “English”)) =26) = 103.

Chinese Records: $((11)$ CNKI $+(12)$ WANGFANG DATA $)=($ Tittle $=$ sedentary behavior $=31$; Tittle $=$ sitting with less move $=28$; Tittle $=$ sitting time $=3$; Tittle $=$ sitting lifestyle $=3$; Tittle $=$ sitting behavior $=11$; Tittle $=$ prolonged sitting behavior $=29$; Tittle $=$ prolonged sitting with less move $=5$; 
Tittle $=$ prolonged sitting with no move $=11$; Tittle $=$ prolonged sitting lifestyle $=4$; Tittle $=$ prolonged sitting time $=2 ;$ Tittle $=$ screen time $=19 ;$ Tittle $=$ television watching time $=29)=175$.

\section{References}

1. Zhang, J.; Chaaban, J. The economic cost of physical inactivity in China. Prev. Med. 2013, 56, 75-78. [CrossRef]

2. Owen, N.; Sparling, P.B.; Healy, G.N.; Dunstan, D.W.; Matthews, C.E. Sedentary behavior: Emerging evidence for a new health risk. Mayo Clin. Proc. 2010, 85, 1138-1141. [CrossRef] [PubMed]

3. Tremblay, M.S.; Aubert, S.; Barnes, J.J.; Saunders, T.; Carson, V.; Latimer, A.; Chastin, S.; Altenburg, T.; Jm Chinapaw, M. Sedentary Behavior Research Network (SBRN) -Terminology Consensus Project process and outcome. Int. J. Behav. Nutr. Phys. Act. 2017, 14, 1-17. [CrossRef] [PubMed]

4. Katzmarzyk, P.T.; Church, T.S.; Craig, C.L.; Bouchard, C. Sitting time and mortality from all causes, cardiovascular disease, and cancer. Med. Sci. Sports Exerc. 2009, 41, 998-1005. [CrossRef] [PubMed]

5. Dunstan, D.; Barr, E.; Healy, G.; Salmon, J.; Shaw, J.; Balkau, B.; Magliano, D.; Cameron, A.; Zimmet, P.; Owen, N. Television viewing time and mortality: The Australian diabetes, obesity and lifestyle study (AusDiab). Circulation 2010, 121, 384-391. [CrossRef]

6. Young, D.R.; Hivert, M.-F.; Alhassan, S.; Camhi, S.M.; Ferguson, J.F.; Katzmarzyk, P.T.; Lewis, C.E.; Owen, N.; Perry, C.K.; Siddique, J.; et al. Sedentary Behavior and Cardiovascular Morbidity and Mortality A Science Advisory from the American Heart Association. Circulation 2016, 134, E262-E279. [CrossRef]

7. Matthews, C.E.; George, S.M.; Moore, S.C.; Bowles, H.R.; Blair, A.; Park, Y.; Troiano, R.P.; Hollenbeck, A.; Schatzkin, A. Amount of time spent in sedentary behaviors and cause-specific mortality in US adults. Am. J. Clin. Nutr. 2012, 95, 437-445. [CrossRef]

8. Saunders, T.J.; Chaput, J.P.; Tremblay, M.S. Sedentary Behaviour as an Emerging Risk Factor for Cardiometabolic Diseases in Children and Youth. Can. J. Diabetes. 2014, 38, 53-61. [CrossRef]

9. Hu, F.B.; Leitzmann, M.F.; Stampfer, M.J.; Colditz, G.A.; Willett, W.C.; Rimm, E.B. Physical Activity and Television Watching in Relation to Risk for Type 2 Diabetes Mellitus in Men. JAMA Intern. Med. 2001, 161, 1542-1548. [CrossRef]

10. Hu, F.B.; Li, T.Y.; Colditz, G.A.; Willett, W.C.; Manson, J.E. Television watching and other sedentary behaviors in relation to risk of obesity and type 2 diabetes mellitus in women. JAMA 2003, 289, 1785-1791. [CrossRef]

11. Edwardson, C.L.; Gorely, T.; Davies, M.J.; Gray, L.J.; Khunti, K.; Wilmot, E.G.; Yates, T.; Biddle, S.J.H. Association of Sedentary Behaviour with Metabolic Syndrome: A Meta-Analysis. PLoS ONE 2012, 7, e34916. [CrossRef] [PubMed]

12. Kerr, J.; Anderson, C.; Lippman, S.M. Physical activity, sedentary behaviour, diet, and cancer: An update and emerging new evidence. Lancet Oncol. 2017, 18, E457-E471. [CrossRef]

13. Lynch, B.M. Sedentary Behavior and Cancer: A Systematic Review of the Literature and Proposed Biological Mechanisms. Cancer Epidemiol. Biomark. Prev. 2010, 19, 2691-2709. [CrossRef] [PubMed]

14. Hoare, E.; Milton, K.; Foster, C.; Allender, S. The associations between sedentary behaviour and mental health among adolescents: A systematic review. Int. J. Behav. Nutr. Phys. Act. 2016, 13, 1-22. [CrossRef]

15. Rezende, L.; Rodrigues, L.M.; Rey, L.J.; Keihan, R.M.V.; Luiz, O. Sedentary Behavior and Health Outcomes: An Overview of Systematic Reviews. PLoS ONE 2014, 9, e105620. [CrossRef]

16. WHO's Global Health Estimates. 2016. Available online: https://data.worldbank.org/indicator/SH.DTH. NCOM.ZS (accessed on 30 June 2019).

17. Zhou, M.; Wang, H.; Zeng, X.; Yin, P.; Zhu, J.; Chen, W.; Li, X.; Wang, L.; Wang, L.; Liu, Y. Mortality, morbidity, and risk factors in China and its provinces, 1990-2017: A systematic analysis for the Global Burden of Disease Study 2017. Lancet 2019, 394, 1145-1158. [CrossRef]

18. Song, Y.; Anette, A.; Ma, J.; Li, L.; Lei, Y.; Randall, S.; Stafford, J.; Prochaska, J. National trends in stunting, thinness and overweight among Chinese school-aged children, 1985-2014. Int. J. Obes. 2018, 43, 402-411. [CrossRef]

19. Li, F.; Mao, L.; Chen, P. Physical activity and prevention of chronic disease in Chinese youth: A public health approach. J. Sport Health Sci. 2019, 8, 512-515. [CrossRef]

20. Wei, Q.; Wang, W.; Gao, K. Effects of Physical Exercise and Sedentary Behavior on the Chronic Diseases Morbidity in a Chinese Adult Population. In MATEC Web of Conferences; EDP Sciences: Xiamen, China, 2015; Volume 22, p. 05018. [CrossRef] 
21. Hu, J.; Ding, N.; Yang, L.; Ma, Y.; Gao, M.; Wen, D. Association between television viewing and early childhood overweight and obesity: A pair-matched case-control study in China. BMC Pediatr. 2019, 19, 184. [CrossRef]

22. Su, C.; Jia, X.F.; Wang, Z.H.; Wang, H.J.; Ouyang, Y.F.; Zhang, B. Longitudinal association of leisure time physical activity and sedentary behaviors with body weight among Chinese adults from China Health and Nutrition Survey 2004-2011. Eur. J. Clin. Nutr. 2017, 71, 383-388. [CrossRef] [PubMed]

23. Yu, L.; Liang, Q.; Zhou, W.; Huang, X.; Hu, L.; You, C.; Li, J.; Wu, Y.; Li, P.; Wu, Q.; et al. Sedentary behavior and the risk of cardiac-cerebral vascular diseases in southern China. Medicine 2018, 97, e12838. [CrossRef] [PubMed]

24. Ye, Q.; Hong, X.; Wang, Z.; Qin, Z.; Li, C.; Lai, Y.; Xu, F. Joint associations of dietary pattern and television viewing with CVD risk factors among urban men and women in China: A cross-sectional study. Br. J. Nutr. 2018, 119, 74-82. [CrossRef] [PubMed]

25. Zhang, T.; Wang, P.; Liu, H.; Wang, L.; Li, W.; Leng, J.; Li, N.; Zhang, S.; Qi, L.; Tuomilehto, J.; et al. Physical Activity, TV Watching Time, Sleeping, and Risk of Obesity and Hyperglycemia in the Offspring of Mothers with Gestational Diabetes Mellitus. Sci. Rep. 2017, 7, 41115. [CrossRef]

26. Leng, J.; Liu, G.; Zhang, C.; Xin, S.; Chen, F.; Li, B.; Tian, H.; Yu, Z.; Tuomilehto, J.; Hu, G.; et al. Physical activity, sedentary behaviors and risk of gestational diabetes mellitus: A population-based cross-sectional study in Tianjin, China. Eur. J. Endocrinol. 2016, 174, 763-773. [CrossRef]

27. Yu, T.; Lu, Q.; Ou, X.; Cao, D.; Yu, Q. Association of sedentary behavior with the expression levels of biomarkers in colorectal cancer: Clinical analysis of 228 patients. Tohoku J. Exp. Med. 2014, 232, 167-176. [CrossRef]

28. Zhang, Y.; Gao, C.; Chen, X.; Zhang, J.; Lu, Z.; Zhang, G.; Shen, T.; Guo, X.; Yin, P. Leisure-time exercise, sedentary behavior and sleeping time and their relationships with hypertension and diabetes among adult residents in Shandong province. Chin. J. Public Health 2018, 34, 803-807.

29. Zhang, J.; Seo, D.C.; Kolbe, L.; Middlestadt, S.; Zhao, W. Associated trends in sedentary behavior and BMI among Chinese school children and adolescents in seven diverse Chinese provinces. Int. J. Behav. Med. 2012, 19, 342-350. [CrossRef]

30. Yu, H.; Schwingel, A. Associations between Sedentary Behavior, Physical Activity, and Out-of-Pocket Health Care Expenditure: Evidence from Chinese Older Adults. J. Aging Phys. Act. 2018, 27, 108-115. [CrossRef]

31. Guthold, R.; Cowan, M.J.; Autenrieth, C.S.; Kann, L.; Riley, L.M. Physical activity and sedentary behavior among schoolchildren: A 34-country comparison. J. Pediatr. 2010, 157, 43-49. [CrossRef]

32. Zhu, Q.; Qu, X. Trends in sedentary behaviors among Chinese children and adolescents in leisure time during 2006-2015. Chin. J. Sch. Health 2019, 40, 827-830+834.

33. Chen, P. Physical activity, physical fitness, and body mass index in the Chinese child and adolescent populations: An update from the 2016 Physical Activity and Fitness in China-The Youth Study. J. Sport Health Sci. 2017, 6, 381-383. [CrossRef] [PubMed]

34. Cai, Y.; Zhu, X.; Wu, X. Overweight, obesity, and screen-time viewing among Chinese school-aged children: National prevalence estimates from the 2016 Physical Activity and Fitness in China-The Youth Study. J. Sport Health Sci. 2017, 6, 404-409. [CrossRef] [PubMed]

35. Zhu, Z.; Tang, Y.; Zhuang, J.; Liu, Y.; Wu, X.; Cai, Y.; Wang, L.; Cao, Z.B.; Chen, P. Physical activity, screen viewing time, and overweight/obesity among Chinese children and adolescents: An update from the 2017 physical activity and fitness in China-The youth study. BMC Public Health 2019, 19, 197. [CrossRef]

36. Xu, C.X.; Zhu, H.H.; Fang, L.; Hu, R.Y.; Wang, H.; Liang, M.B.; Zhang, J.; Lu, F.; He, Q.F.; Wang, L.X. Gender disparity in the associations of overweight/obesity with occupational activity, transport to/from work, leisure-time physical activity, and leisure-time spent sitting in working adults: A cross-sectional study. J. Epidemiol. 2017, 27, 401-407. [CrossRef]

37. Zhu, Z.; Zhou, Z.; Xi, Y.; Zhang, F.; Lu, Q.; Zhang, F.; Huang, D.; Ren, H.; Wang, K.; Yin, Z. Sedentary Behavior Predicts Changes in Cardiometabolic Risk in Professional Workers: A One-Year Prospective Study. J. Occup. Environ. Med. 2016, 58, e117-e123. [CrossRef]

38. Peng, G.P.; Liang, S.J.; Carlton, E.; Jiang, Q.; Wu, J.; Wang, L.V.; Remais, J. Urbanisation and health in China. Lancet 2012, 379, 843-852. 
39. Owen, N.; Salmon, J.; Koohsari, M.J.; Turrell, G.; Giles-Corti, B. Sedentary behaviour and health: Mapping environmental and social contexts to underpin chronic disease prevention. Br. J. Sports Med. 2014, 48, 174-177. [CrossRef]

40. An, R.; Shen, J.; Yang, Q.; Yang, Y. Impact of Built Environment on Physical Activity and Obesity among Children and Adolescents in China: A Narrative Systematic Review. J. Sport Health Sci. 2019, 8, 153-169. [CrossRef]

41. Guo, C.; Zhang, B.; Wang, H.; Feng, G.; Li, J.; Su, C.; Zhang, J.; Wang, Z.; Du, W. A Scan of Obesogenic Environments and a Spatial Inference of Obesity Prevalence in Chinese Children and Adolescents: Based on the Chinese Health and Nutrition Survey 2011 Data. Biomed. Environ. Sci. BES 2018, 31, 729-739.

42. Chen, F.; Liu, G. Population aging in China. International handbook of population aging. Springer Sci. Bus. Media 2009, 1, 157-172.

43. Chen, R.; Xu, P.; Song, P.; Wang, M.; He, J. China has faster pace than Japan in population aging in next 25 years. Biosci. Trends 2019, 13, 287-291. [CrossRef]

44. Cui, Z.; Hardy, L.L.; Dibley, M.J.; Bauman, A. Temporal trends and recent correlates in sedentary behaviours in Chinese children. Int. J. Behav. Nutr. Phys. Act. 2011, 8, 93. [CrossRef] [PubMed]

45. Tudor-Locke, C.; Ainsworth, B.E.; Adair, L.; Du, S.; Popkin, B. Physical activity and inactivity in Chinese school-aged youth: The China Health and Nutrition Survey. Int. J. Obes. 2003, 27, 1093-1099. [CrossRef] [PubMed]

46. State Council of China. Healthy China 2030 Blueprint. 2016. Available online: http://www.gov.cn/xinwen/ 2016-10/25/content_5124174.htm (accessed on 25 October 2016).

47. Arskey, H.; O’Malley, L. Scoping studies: Towards a methodological framework. Int. J. Soc. Res. Methodol. 2005, 8, 19-32.

48. Colquhoun, H.L.; Levac, D.; O’Brien, K.K.; Straus, S.; Tricco, A.C.; Perrier, L.; Kastner, M.; Moher, D. Scoping reviews: Time for clarity in definition, methods, and reporting. J. Clin. Epidemiol. 2014, 67, 1291-1294. [CrossRef]

49. Peters, M.; Godfrey, C.; Khalil, H.; McInerney, P.; Parker, D.; Soares, C. Guidance for conducting systematic scoping reviews. Int. J. Evid. Based Healthc. 2015, 13, 141-146. [CrossRef]

50. Tremblay, M. Standardised use of the terms" sedentary" and" sedentary behaviours": Letter to the editor. Afr. J. Phys. Health Educ. Recreat. Danc. 2012, 18, 200-204.

51. O’Donoghue, G.; Perchoux, C.; Mensah, K.; Lakerveld, J.; van der Ploeg, H.; Bernaards, C.; Chastin, S.; Simon, C.; O'Gorman, D.; Nazare, J.A. A systematic review of correlates of sedentary behaviour in adults aged 18-65 years: A socio-ecological approach. BMC Public Health 2016, 16, 163. [CrossRef]

52. Liangruenrom, N.; Suttikasem, K.; Craike, M.; Bennie, J.A.; Biddle, S.J.; Pedisic, Z. Physical activity and sedentary behaviour research in Thailand: A systematic scoping review. BMC Public Health 2018, 18, 733. [CrossRef]

53. Li, C.; Haegele, J.A.; Wu, L. Comparing physical activity and sedentary behavior levels between deaf and hearing adolescents. Disabil. Health J. 2019, 12, 514-518. [CrossRef] [PubMed]

54. Lai, A.; Stewart, S.; Wan, A.; Thomas, C.; Tse, J.; Ho, D.; Chan, S.; Lam, T.H. Development and feasibility of a brief Zero-time Exercise intervention to reduce sedentary behaviour and enhance physical activity: A pilot trial. Health Soc. Care Commun. 2019, 27, e233-e245. [CrossRef] [PubMed]

55. Wang, K.; Xue, Y.; Fam, X.; Huang, T.; Chen, Z. Sedentary behaviors, psychological status, and sleep quality in Chinese university students. Soc. Behav. Personal. Int. J. 2019, 47, 1-10. [CrossRef]

56. Gong, W.J.; Fong, D.Y.; Wang, M.P.; Lam, T.H.; Chung, T.W.; Ho, S.Y. Increasing socioeconomic disparities in sedentary behaviors in Chinese children. BMC Public Health 2019, 19, 754. [CrossRef]

57. Cerin, E.; Sit, C.H.; Wong, S.H.; Huang, Y.J.; Gao, G.Y.; Lai, P.C.; Macfarlane, D.J.; Barnett, A. Relative contribution and interactive effects of psychological, social, and environmental correlates of physical activity, sedentary behaviour, and dietary behaviours in Hong Kong adolescents. Hong Kong Med. J. 2019, 25, 34-39.

58. Zhu, Y.; Blumenthal, J.A.; Shi, C.; Jiang, R.; Patel, A.; Zhang, A.; Yu, X.; Gao, R.; Wu, Y. Sedentary Behavior and the Risk of Depression in Patients with Acute Coronary Syndromes. Am. J. Cardiol. 2018, 121, 1456-1460. [CrossRef]

59. Zhu, X.; Haegele, J.A.; Tang, Y.; Wu, X. Prevalence and Demographic Correlates of Overweight, Physical Activity, and Screen Time Among School-Aged Children in Urban China: The Shanghai Study. Asia Pac. J. Public Health 2018, 30, 118-127. [CrossRef] 
60. Yu, L.; Liang, Q.; Zhou, W.; Huang, X.; Hu, L.; You, C.; Li, J.; Wu, Y.; Li, P.; Wu, Q.; et al. Association between physical activity and stroke in a middle-aged and elderly Chinese population. Medicine 2018, 97, e13568. [CrossRef]

61. Ye, S.; Chen, L.; Wang, Q.; Li, Q. Correlates of screen time among 8-19-year-old students in China. BMC Public Health 2018, 18, 467. [CrossRef]

62. Wang, H.; Zhong, J.; Hu, R.; Fiona, B.; Yu, M.; Du, H. Prevalence of high screen time and associated factors among students: A cross-sectional study in Zhejiang, China. BMJ Open 2018, 8, e021493. [CrossRef]

63. Liu, K.; Xu, Y.; Wang, S.; Shi, R.; Gong, S.; Li, X.; Yang, Y.; Chen, X. Buddhist Activities related to Sedentary behavior and Hypertension in Tibetan monks. J. Hum. Hypertens. 2019, 33, 756-762. [CrossRef] [PubMed]

64. Jin, J.; Zhuang, J.; Zhu, Z.; Wang, S.; Chen, P.; Zhu, W. Energy expenditure of type-specific sedentary behaviors estimated using sensewear mini armband: A metabolic chamber validation study among adolescents. Kinesiology 2018, 50, 52-56. [CrossRef]

65. Hu, B.Y.; Johnson, G.K.; Wu, H. Screen time relationship of Chinese parents and their children. Child. Youth Serv. Rev. 2018, 94, 659-669. [CrossRef]

66. An, R.; Yu, H. Impact of ambient fine particulate matter air pollution on health behaviors: A longitudinal study of university students in Beijing, China. Public Health 2018, 159, 107-115. [CrossRef] [PubMed]

67. Zhu, X.; Haegele, J.A.; Tang, Y.; Wu, X. Physical Activity and Sedentary Behaviors of Urban Chinese Children: Grade Level Prevalence and Academic Burden Associations. Biomed Res. Int. 2017, 2017, 1-7. [CrossRef] [PubMed]

68. Yan, H.; Zhang, R.; Oniffrey, T.M.; Chen, G.; Wang, Y.; Wu, Y.; Zhang, X.; Wang, Q.; Ma, L.; Li, R. Associations among Screen Time and Unhealthy Behaviors, Academic Performance, and Well-Being in Chinese Adolescents. Int. J. Environ. Res. Public Health 2017, 14, 596. [CrossRef] [PubMed]

69. Xinping, W.; Yu, Z.; Xiaodong, J.; Xiangui, H.; Shurong, Z.; Hui, W.; Meihua, S.; Jiajie, Z.; Wei, X.; Zang, Y. Age, period and cohort effects and the predictors of physical activity and sedentary behaviour among Chinese children, from 2004 to 2011. BMC Public Health 2017, 17, 1-11.

70. Wu, X.; Tao, S.; Rutayisire, E.; Chen, Y.; Huang, K.; Tao, F. The relationship between screen time, nighttime sleep duration, and behavioural problems in preschool children in China. Eur. Child Adolesc. Psychiatry 2017, 26, 541-548. [CrossRef]

71. Song, J.Y.; Song, Q.Y.; Wang, S.; Ma, J.; Wang, H.J. Physical activity and sedentary behaviors modify the association between melanocortin 4 receptor gene variant and obesity in Chinese children and adolescents. PLoS ONE 2017, 12, e0170062. [CrossRef]

72. Li, M.; Xue, H.; Wang, W.; Wang, Y. Parental Expectations and Child Screen and Academic Sedentary Behaviors in China. Am. J. Prev. Med. 2017, 52, 680-689. [CrossRef]

73. Ku, P.W.; Liu, Y.T.; Lo, M.K.; Chen, L.J.; Stubbs, B. Higher levels of objectively measured sedentary behavior is associated with worse cognitive ability: Two-year follow-up study in community-dwelling older adults. Exp. Gerontol. 2017, 99, 110-114. [CrossRef] [PubMed]

74. Hong, R.; Zhou, Z.; Liu, W.; Wang, X.; Yin, Z. Excessive homework, inadequate sleep, physical inactivity and screen viewing time are major contributors to high paediatric obesity. Acta Paediatr. 2017, 106, 120-127.

75. Gao, Y.; Cronin, N.J.; Nevala, N.; Finni, T. Validity of long-term and short-term recall of occupational sitting time in Finnish and Chinese office workers. J. Sport Health Sci. 2017, 2017, 1-8. [CrossRef] [PubMed]

76. Dong, F.; Howard, A.G.; Herring, A.H.; Thompson, A.L.; Adair, L.S.; Popkin, B.M.; Aiello, A.E.; Zhang, B.; Gordon-Larsen, P. Longitudinal associations of away-from-home eating, snacking, screen time, and physical activity behaviors with cardiometabolic risk factors among Chinese children and their parents. Am. J. Clin. Nutr. 2017, 106, 168-178. [CrossRef] [PubMed]

77. Dearth-Wesley, T.; Howard, A.G.; Wang, H.; Zhang, B.; Popkin, B.M. Trends in domain-specific physical activity and sedentary behaviors among Chinese school children, 2004-2011. Int. J. Behav. Nutr. Phys. Act. 2017, 14, 141. [CrossRef]

78. Chen, P.; Song, Q.; Han, J.; Xu, H.; Chen, T.; Xu, J.; Cheng, Y. Sitting time and occupational and recreational physical activity in relation to the risk of esophageal squamous cell Carcinoma. OncoTargets Ther. 2017, 10, 4787-4794. [CrossRef]

79. Zheng, W.; Chen, Y.; Zhao, A.; Xue, Y.; Zheng, Y.; Mu, Z.; Wang, P.; Zhang, Y. Associations of sedentary behavior and physical activity with physical measurements and dyslipidemia in school-age children: A cross-sectional study. BMC Public Health 2016, 16, 1186. [CrossRef] 
80. Huang, W.Y.; Wong, S.H.S.; Gang, H.E.; Salmon, J.O. Isotemporal Substitution Analysis for Sedentary Behavior and Body Mass Index. Med. Sci. Sports Exerc. 2016, 48, 2135-2141. [CrossRef]

81. Xue, H.; Tian, G.; Duan, R.; Quan, L.; Zhao, L.; Yang, M.; Libuda, L.; Muckelbauer, R.; Cheng, G. Sedentary Behavior Is Independently Related to Fat Mass among Children and Adolescents in South China. Nutrients 2016, 8, 667. [CrossRef]

82. Xiao, J.; Shen, C.; Chu, M.J.; Gao, Y.X.; Xu, G.F.; Huang, J.P.; Xu, Q.Q.; Cai, H. Physical Activity and Sedentary Behavior Associated with Components of Metabolic Syndrome among People in Rural China. PLoS ONE 2016, 11, e0147062. [CrossRef]

83. Wei, H.; Qu, H.; Wang, H.; Deng, H. Associations between sitting time and non-alcoholic fatty liver diseases in Chinese male workers: A cross-sectional study. BMJ Open 2016, 6, e011939. [CrossRef] [PubMed]

84. Wang, S.; Song, J.; Shang, X.; Chawla, N.; Yang, Y.; Meng, X.; Wang, H.; Ma, J. Physical activity and sedentary behavior can modulate the effect of the PNPLA3 variant on childhood NAFLD: A case-control study in a Chinese population. BMC Med. Genet. 2016, 17, 90. [CrossRef] [PubMed]

85. Liu, M.; Ming, Q.; Yi, J.; Wang, X.; Yao, S. Screen Time on School Days and Risks for Psychiatric Symptoms and Self-Harm in Mainland Chinese Adolescents. Front. Psychol. 2016, 7, 574. [CrossRef] [PubMed]

86. Huang, X.H.; Zhang, J.; Chen, Z.J.; Qu, X.P.; Gu, F.; Ma, H.Y.; Liu, T.J.; Xu, L.W. A transtheoretical model-based analysis of sedentary behaviors in Chinese high school students. Int. J. Clin. Exp. Med. 2016, 9, 3820-3830.

87. Fei, D.; Green Howard, A.; Herring, A.H.; Thompson, A.L.; Adair, L.S.; Popkin, B.M.; Aiello, A.E.; Bing, Z.; Gordon-Larsen, P. Parent-child associations for changes in diet, screen time, and physical activity across two decades in modernizing China: China Health and Nutrition Survey 1991-2009. Int. J. Behav. Nutr. Phys. Act. 2016, 13, 1-11.

88. Chen, X.; Gangqiang, D.; Zhong, D.; Xinwei, Z.; Liuxia, Y.; Bo, C.; Wenhua, Z. Associations of Domain-Specific Physical Activity with Leisure-Time Sedentary Behaviors in Chinese Professionals. J. Occup. Environ. Med. 2016, 58, 778-783. [CrossRef]

89. Xin, W.; Qing-Min, L.; Yan-Jun, R.; Jun, L.; Li-Ming, L. Family influences on physical activity and sedentary behaviours in Chinese junior high school students: A cross-sectional study. BMC Public Health 2015, 15, 1-9.

90. Wu, X.; Tao, S.; Zhang, Y.; Zhang, S.; Tao, F. Low physical activity and high screen time can increase the risks of mental health problems and poor sleep quality among Chinese college students. PLoS ONE 2015, 10, e0119607. [CrossRef]

91. Duan, J.; Hu, H.; Wang, G.; Arao, T. Study on Current Levels of Physical Activity and Sedentary Behavior among Middle School Students in Beijing, China. PLoS ONE 2015, 10, e0133544. [CrossRef]

92. Anthony, B.; Cerin, E.; Ching, C.S.; Johnston, J.M.; Lee, R.S. Neighbourhood environment, sitting time and motorised transport in older adults: A cross-sectional study in Hong Kong. BMJ Open 2015, 5, e007557.

93. Zeng, X.; Sheiham, A.; Sabbah, W. The association between dental caries and television viewing among Chinese adolescents in Guangxi, China. BMC Oral Health 2014, 14, 138. [CrossRef] [PubMed]

94. Ye, S.; Song, A.; Yang, M.; Ma, X.; Fu, X.; Zhu, S. Duration of television viewing and bone mineral density in Chinese women. J. Bone Miner. Metab. 2014, 32, 324-330. [CrossRef] [PubMed]

95. Xie, Y.J.; Stewart, S.M.; Lam, T.H.; Viswanath, K.; Chan, S.S. Television Viewing Time in Hong Kong Adult Population: Associations with Body Mass Index and Obesity. PLoS ONE 2014, 9, 1-7. [CrossRef] [PubMed]

96. Jiang, X.X.; Hardy, L.L.; Ding, D.; Baur, L.A.; Shi, H.J. Recreational screen-time among Chinese adolescents: A cross-sectional study. J. Epidemiol. 2014, 24, 397-403. [CrossRef] [PubMed]

97. Feng, Q.; Zhang, Q.L.; Du, Y.; Ye, Y.L.; He, Q.Q. Associations of physical activity, screen time with depression, anxiety and sleep quality among Chinese college freshmen. PLoS ONE 2014, 9, e100914. [CrossRef] [PubMed]

98. Chen, Y.; Zheng, Z.; Yi, J.; Yao, S. Associations between physical inactivity and sedentary behaviors among adolescents in 10 cities in China. BMC Public Health 2014, 14, 744. [CrossRef] [PubMed]

99. Cerin, E.; Sit, C.; Huang, W.Y.; Barnett, A.; Macfarlane, D.; Wong, S. Repeatability of self-report measures of physical activity, sedentary and travel behaviour in Hong Kong adolescents for the iHealt $(\mathrm{H})$ and IPEN-Adolescent studies. BMC Pediatr. 2014, 14, 142. [CrossRef]

100. Wang, C.; Chen, P.; Zhuang, J. A national survey of physical activity and sedentary behavior of Chinese city children and youth using accelerometers. Res. Q. Exerc. Sport 2013, 84, S12-S28. [CrossRef]

101. Huang, W.Y.; Wong, S.; Salmon, J. Correlates of physical activity and screen-based behaviors in Chinese children. J. Sci. Med. Sport 2013, 16, 509-514. [CrossRef] 
102. Du, H.; Bennett, D.; Li, L.; Whitlock, G.; Guo, Y.; Collins, R.; Chen, J.; Bian, Z.; Hong, L.S.; Feng, S. Physical activity and sedentary leisure time and their associations with BMI, waist circumference, and percentage body fat in 0.5 million adults: The China Kadoorie Biobank study. Am. J. Clin. Nutr. 2013, 97, 487-496.

103. Cui, Z.; Shah, S.; Yan, L.; Pan, Y.; Gao, A.; Shi, X.; Wu, Y.; Dibley, M.J. Effect of a school-based peer education intervention on physical activity and sedentary behaviour in Chinese adolescents: A pilot study. BMJ Open 2012, 2, e000721. [CrossRef] [PubMed]

104. Soos, I.; Biddle, S.J.H.; Karsai, I.; Shuhong, L.; Hamar, P. Physical Activity, Sedentary Behaviours, and Snacking in Youth of Northeast England and Harbin, Northeast China. Asian J. Exerc. Sports Sci. 2011, 8, 16-28.

105. Ding, D.; Sallis, J.F.; Hovell, M.F.; Jianzhong, D.; Miao, Z.; Haiying, H.; Owen, N. Physical activity and sedentary behaviours among rural adults in Suixi, China: A cross-sectional study. Int. J. Behav. Nutr. Phys. Act. 2011, 8, 37-44. [CrossRef] [PubMed]

106. Cao, H.; Qian, Q.; Weng, T.; Yuan, C.; Sun, Y.; Wang, H.; Tao, F. Screen time, physical activity and mental health among urban adolescents in China. Prev. Med. 2011, 53, 316-320. [CrossRef]

107. Sarah, A.P.; Brown, J.D.; Du, S.; Zimmer, C.R.; Zhao, X.; Zhai, F. Television use and snacking behaviors among children and adolescents in China. J. Adolesc. Health 2010, 46, 339-345.

108. Liu, Y.; Wang, M.; Tynjälä, J.; Lv, Y.; Villberg, J.; Zhang, Z.; Kannas, L. Test-retest reliability of selected items of Health Behaviour in School-aged Children (HBSC) survey questionnaire in Beijing, China. BMC Med. Res. Methodol. 2010, 10, 73. [CrossRef]

109. Chen, X.; Pang, Z.; Li, K. Dietary fat, sedentary behaviors and the prevalence of the metabolic syndrome among Qingdao adults. Nutr. Metab. Cardiovasc. Dis. 2009, 19, 27-34. [CrossRef]

110. Xu, F.; Li, J.S.; Ware, R.; Owen, N. Associations of television viewing time with excess body weight among urban and rural high-school students in regional mainland China. Public Health Nutr. 2007, 11, 891-896. [CrossRef]

111. Li, M.; Dibley, M.J.; Sibbritt, D.W.; Zhou, X.; Yan, H. Physical Activity and Sedentary Behavior in Adolescents in Xi'an City, China. J. Adolesc. Health 2007, 41, 99-101. [CrossRef]

112. Li, C.L.; Lin, J.D.; Lee, S.J.; Tseng, R.F. Associations between the metabolic syndrome and its components, watching television and physical activity. Public Health 2007, 121, 83-91. [CrossRef]

113. Zhang, M.; Xie, X.; Lee, A.H.; Binns, C.W. Sedentary behaviours and epithelial ovarian cancer risk. Cancer Causes Control. 2004, 15, 83-89. [CrossRef] [PubMed]

114. Ma, G.S.; Li, Y.P.; Hu, X.Q.; Ma, W.J.; Wu, J. Effect of television viewing on pediatric obesity. Biomed. Environ. Sci. 2002, 15, 291-297. [PubMed]

115. Zhang, L. Empirical Research on the Relationship between Physical Activity, Sedentary Behavior and Physical Health of Adolescents. J. Guangzhou Sport Univ. 2019, 39, 101-104.

116. Xu, Y.; Yan, Q.; Tong, L. Associations between screen time and attention deficit and hyperactivity disorder symptoms among urban and rural preschoolers. Chin. J. Child Health Care 2019, 27, 997-1001.

117. Xiong, Q.; Liu, J.; Shi, H.; Wang, R.; Ren, D.; Liu, X.; Liu, J.; Lei, T.; Cheng, S. Study on the correlations between screen time and parent-child relationship, social ability and behavioral problems of school children. Matern. Child Health Care China 2019, 34, 899-904.

118. Wang, L. Evaluation of the effect of transtheoretical model on sedentary behavior intervention of primary and middle school students. Contemp. Sports Technol. 2019, 9, 237-238.

119. Tian, T.; Gu, B. Development and evaluation on reliability and validity of adult sedentary behavior questionnaire in china. Chin. J. Health Educ. 2019, 35, 525-529+545.

120. Tao, X.J.; Yang, J.J.; Fan, Y.N.; Cai, H.Z.; Zhao, Y.; Gao, Q.H. Correlation between snacks, physical activity, sedentary behavior, overweight, obesity and sociodemographic characteristics. Matern. Child Health Care China 2019, 34, 2579-2582.

121. Ma, X.R.; Cai, Y.J.; Chen, S.T.; Li, K.; Zhuang, P. Relationships between the basic movement skills and sedentary behaviors of children aged 3-6. J. Phys. Educ. 2019, 26, 123-128.

122. He, M.; Li, J.Y.; Meng, L. A Current Situation and Countermeasure Research Study of College Students' Physical Activity and Sedentary Behavior: Taking Wuhan Commercial College as an Example. Fujian Sports Sci. Technol. 2019, 38, 43-46. 
123. Feng, Y.H.; Yan, L.; Ma, S.; Wu, S.S.; Shen, Z.Z.; Wang, Y.W.; Ma, L.K.; Jiang, Y. Associations of physical activity and sedentary behavior with depressive symptoms of pregnant women in the first trimester. Mod. Prev. Med. 2019, 46, 2179-2182+2191.

124. Zhou, Y.; Feng, Q. Research on Sedentary Behavior among First-year High-school Students of Xicheng District of Beijing. Chin. J. Sports Med. 2018, 37, 833-838.

125. Zhang, B.; Sun, J.H. Sedentary behavior evaluation system for office workers based on Delphi method. J. Environ. Occup. Med. 2018, 35, 434-437.

126. Zhan, C.Z.; Chen, X.A.; Fang, Z.; He, J. Study on the Sedentary and Sedentary Life Style of College Students in Western Hunan. J. Anhui Sports Sci. 2018, 39, 54-59.

127. Xiong, R.; Yuan, L.F.; Yang, J.G.; Wang, Y.; Bo, J.; Zhao, Y.Y.; Liu, L.S.; Li, W. Correlation Study Between Bicycle Ownership Status and Physical Activity, Time of Sitting, Overweight or Obesity. Chin. Circ. J. 2018, 33, 251-255.

128. Xiao, P. Survey on lifestyle and physical health of civil servants aged $45-59$ years in Ning Xia. Fujian Sports Sci. Technol. 2018, 37, 21-24.

129. Xiao, M.L.; Zhang, C.M.; Xiao, Y.L.; Tian, J.; Zheng, X. Relationship between dietary pattern, TV viewing and cardiovascular risk factors. J. Med. Pest Control. 2018, 34, 55-58.

130. Wang, J.; Bo, H.; Song, D.W.; Chen, D.; Dong, Y.Q. Correlation between sedentary behavior and subjective well-being related index among children and adolescents. Chin. J. Sch. Health 2018, 39, 1495-1498+1501.

131. Wang, Z.S.; Chen, Y.; Wei, Y. Relationship between Sedentary Behavior and BMI in Junior Middle School Students in Guangzhou. Hubei Sports Sci. 2018, 37, 135-139+160.

132. Ma, D.D. Study on sedentary behavior and physical inactivity of medical university students. Sport 2018, 14, 34-35+39.

133. Liu, H.B. The relation between Physical Exercise, Self-esteem, Goal Orientation and Sedentary Behavior in middle school students. J. Southwest China Norm. Univ. (Nat. Sci. Ed.) 2018, 43, 137-142.

134. Li, B.W.; Jia, M.; Zhou, Y.; Su, H.P.; Lu, C.H.; Wang, Y.; Wang, Z.Z. Physical inactivity and sedentary behaviors in relation to prevalence of dysglycemia. J. Wuhan Inst. Phys. Educ. 2018, 52, 95-100.

135. Jiang, D.L. Research on Screening Sedentary Behavior of Primary and Middle School Students in China from the Perspective of Social Ecology. Contemp. Sports Technol. 2018, 8, 203-208.

136. Dong, H.; Wang, R.H.; Dai, J. Effects of Different Doses of Exercise on Cardiovascular Health of Middle-Aged Sedentary Women. J. Beijing Sport Univ. 2018, 41, 65-72.

137. Dong, H.; Dai, J. Research on Dose-Effect Relationship between Physical Activity and Cardiovascular Health Risk Factors in Sedentary Women. China Sch. Phys. Educ. (High. Educ.) 2018, 5, 78-87.

138. Cai, X.; Han, J.; Ju, C.P.; Chen, X.; Qiu, S.H.; Sun, Z.L. Effects of Pedometer Intervention on Exercise Amount and Sedentary Time in Patients with Type 2 Diabetes. Chin. Gen. Pract. 2018, 21, 3313-3318.

139. Zhou, J.; Zhou, Q.; Wang, D.P.; Zhang, T.; Wang, H.J.; Song, Y.; He, H.Z.; Wang, P.Y.; Liu, A.P. Associations of sedentary behavior and physical activity with dyslipidemia. J. Peking Univ. (Health Sci.) 2017, 49, 418-423.

140. Xu, Y.Q.; Lv, C.H.; Zhan, H.R. The relationship between children's physical activity, screen time and overweight/obesity. Shanxi Med. J. 2017, 46, 883-885.

141. Xu, W.; Xing, X.Y.; Xie, J.R.; Chen, Y.J.; He, Q.; Li, R.; Cao, D.; Wu, Q.S.; Jia, S.C.; Liu, Z.R. Prevalence of physical exercise and sedentary behavior in adults in Anhui, 2013. Dis. Surveill. 2017, 32, 778-783.

142. Wei, X.L.; Hu, Y.H.; Zhang, Z.J. Sedentary behavior status and its association with metabolic syndrome or other components in diabetes patients. Chin. J. Prev. Control Chronic Dis. 2017, 25, 253-256.

143. Tang, Y.M.; He, T.J.; Li, Q.; Pan, J.J.; Zhang, Q.J.; Zhang, L. Leisure time physical activity and sedentary behavior of adults in Hubei in 2013. Chin. Prev. Med. 2017, 18, 774-779.

144. Peng, L.; Han, P. Relationship between physical activity levels, sitting time and glycolipid metabolism of type II diabetics. Mod. Prev. Med. 2017, 44, 4391-4394.

145. Liu, W.J.; Xiong, L.H.; Lin, R.; Liu, W.; Chen, S.Y.; Lin, L.; Guo, C.S. Correlation between sedentary behaviors and motor constitution among primary school students in Guangzhou urban area. Chin. J. Sch. Health 2017, $38,42-44+47$.

146. Li, H.; Dong, Z.; Ma, A.J.; Dong, J.; Fang, K.; Xie, C.; Qi, K.; Xie, J.; Zhou, Y.; Zhao, Y. The spare screen time and its distribution characteristics among adult residents in Beijing. Chin. J. Health Educ. 2017, 33, 600-603+611.

147. Guo, Q.; Wang, X.Z.; Jiang, J.B. The Patterns of Physical Activity and Sedentary Behavior in Chinese Children and Adolescents. China Sport Sci. 2017, 37, 17-29. 
148. Ye, S.Y.; Guo, J. Status, trends and influencing factors of adult physical exercise and sedentary behavior in China. J. Cap. Univ. Phys. Educ. Sports 2016, 28, 365-369+375.

149. Lu, S.R.; Yu, H.; Han, R.Q.; Su, J.; Pan, X.Q.; Zhang, Y.Q.; Zhou, J.Y.; Wu, M. Sedentary behavior and risk of cardio-cerebrovascular disease mortality: A nested case-control study. Chin. J. Public Health 2016, 32, 1467-1469.

150. Lu, L.; Jin, C.Q.; Hu, H.Q. Relation between sedentary behavior and sleep quality in younger occupational population. Health Educ. Health Promot. 2016, 11, 321-323.

151. Liu, M.; Liu, H.; Zhang, Q.J.; Ma, J.X.; Bai, Y.M. Physical activity and sedentary behavior of high-risk population of chronic diseases in occupational places in Hubei Province. Chin. J. Prev. Control Chronic Dis. 2016, 24, 688-690.

152. Li, Y.J. Sedentary behavior and physical activity in patients with cardiovascular disease. J. Math. Med. 2016, $29,57-59$.

153. Li, P.H.; Lv, Y.; Wang, M. Sedentary behavior and its impact on health among children and adolescents. Chin. J. Sch. Health 2016, 37, 1476-1479.

154. Li, G.Q.; Jiang, C.M.; Li, M.H. Study on patterns of sedentary behavior in Chinese adults. China Sport Sci. 2016, 36, 52-60+66.

155. Jia, X.F.; Wang, H.J.; Wang, D.T.; Su, C.; Zhang, J.; Jiang, J.R.; Ou-Yang, Y.F.; Zhang, B. Analysis of physical activity and sedentary behaviors in children and adolescents from 12 provinces/municipalities in China. J. Hyg. Res. 2016, 45, 394-397.

156. Du, B.; Tao, F.B. Investigation of diet behaviors and sedentary lifestyle in children with obesity. Chin. J. Sch. Health 2016, 37, 511-513.

157. Cheng, L.; Li, Q.; Li, Y.; Ma, J.; Wang, H.J. Association of physical activities, sedentary behaviors with overweight/obesity in 9-11 years old Chinese primary school students. J. Peking Univ. (Health Sci.) 2016, 48, 436-441.

158. Ye, S.Y. Measurement of Sedentary Behavior and its Association with Depression in College Students. China J. Health Psychol. 2015, 23, 1107-1110.

159. Yang, D.L.; Luo, C.Y.; Zhou, Y.F.; Jiang, H.F.; Wang, X.D. Sedentary behaviors and obesity among primary school students in Shanghai. Chin. J. Sch. Health 2015, 36, 983-985.

160. Wang, Z.Q.; Chang, S.Z.; Sun, Y.L.; Guo, J. Sedentary Behaviors and Physical Activity Patterns among Secondary Students. J. Tianjin Univ. Sport 2015, 30, 277-281.

161. Luo, C.Y.; Zhou, Y.F.; Lu, Q.; Wang, X.D.; Chen, J.; Zhao, Y.; Jiang, H.F.; Tang, H.Y.; Feng, X.G. The association between screen time and trait anxiety among middle school students in Shanghai. Chin. J. Sch. Health 2015, 36, 979-982.

162. Jin, Y.; Zhao, J. Effects of pregnancy exercise and sitting behavior on blood sugar, lipid metabolism and neonates in primipara. Matern. Child Health Care China 2015, 30, 6473-6476.

163. Jiang, W.; Wang, W.J.; Zhang, J.Y.; Feng, G.Y.; Fu, Z.T.; Ma, J.X. Physical activity and sedentary behaviors among 35-74 years old rural residents in Ningyang, Shangdong province, 2010. Chin. J. Public Health Manag. 2015, 31, 252-254.

164. Huang, C.Y.; Hong, P.; He, Z.H.; Zhao, J.X.; Li, R.; Wang, M.; Tian, Y. Relationship between Television Time and Risk of Cardiovascular Event Cross-study Based on Heart Rate Recovery and Heart Rate Variability. China Sport Sci. 2015, 35, 48-54.

165. Deng, Q.; Chen, X.R.; Wang, Z.H.; Zhang, M.; Li, Y.C.; Huang, Z.J. Television viewing time of Chinese adults: Associations with body mass index and obesity. Chin. J. Front. Med. Sci. (Electron. Version) 2015, 7, 46-50.

166. Deng, Q.; Tao, R.; Wang, L.M.; Huang, Z.J.; Zhang, M.; Zhao, Y.J. Association of sedentary time with body mass index and obesity of Chinese floating population 18-59 years old in 2012. Chin. J. Prev. Control Chronic Dis. 2015, 23, 405-408.

167. Yi, K.H.; Luo, C.Y.; Zhou, Y.F.; Lu, Q.; Wang, X.D.; Chen, J.; Zhao, Y.; Jiang, H.F. Association between Screen Time and Obesity among Middle School Students in Shanghai. J. Environ. Occup. Med. 2014, 31, 452-455.

168. Song, Y.J.; Dong, S.M.; Jiang, Y.R.; Sun, W.Q.; Wang, Y.; Jiang, F. Association between television viewing time and dietary patterns among preschool children. Chin. J. Evid. Based Pediatr. 2014, 9, 447-451.

169. Hu, H.Q.; Shi, H.J.; Wang, H.Y.; Xiang, J.X. Sedentary behaviors on weekend and it's association with overweight and obesity among secondary school students of Yuhang District in Hangzhou City. Chin. J. Sch. Health 2014, 3, 1125-1126+1130. 
170. Fan, S.; Chen, J.C.; Huang, J.F.; Li, J.X.; Cao, J.; Yu, L.; Deng, Y.; Chen, N.Y.; Xu, L.H.; Hu, Y.H. Relationship Between Television Viewing Time and the Incidence of Type 2 Diabetes Mellitus in Chinese Adults: A Prospective Cohort Study. Chin. Circ. J. 2014, 29, 372-376.

171. Cai, F.H.; Zhang, X.S.; Xiong, J.Y.; Liu, Z.J. Correlation Study on Sedentary behavior, Physical activity and Bong Mineral Density of Student in Late Adolescence. China Sch. Phys. Educ. (High. Educ.) 2014, 1, 84-88.

172. Yang, Y.; Deng, H.C.; Long, J.; Su, Y.X.; Yang, M.; Qu, H.; Hu, Z.P.; Deng, M.; Wang, H.; Wei, H.L. The relationship between sitting and watching television time and impaired glucose regulation, type 2 diabetes mellitus in Chongqing. Chongqing Med. 2013, 42, 4168-4169+4172.

173. Wu, J.G.; Liu, X.X.; Tang, C.X.; Jin, B.; Gu, P.; Dai, H.W. The effects of sedentary habits and physical exercise on metabolic syndrome in urban residents of Shanghai. Chin. J. Prev. Control Chronic Dis. 2013, 21, 18-21.

174. Luo, C.Y.; Yu, J.; Wang, P.F.; Liu, F.; Zhao, Y.; Hu, G.Q. Adolescents' sedentary behaviors and related factors in Shanghai. Shanghai J. Prev. Med. 2013, 25, 657-660.

175. Li, X.Y.; Qi, S.G.; Wang, L.H. Analyzing the situation of leisure-time physical exercise and sedentary behaviors in Chinese female medical doctors during 2011. Chin. J. Prev. Control Chronic Dis. 2013, 21, 297-300.

176. Qian, Q.W.; Sun, Y.; Wang, C.H.; Jing, G.Q.; Zhu, F.; Dong, J. Impact of aerobic exercises and sedentary behaviors on psychology and cognition among middle school students in Bengbu. Chin. J. Sch. Health 2012, 33, 1479-1481.

177. Liu, W.; Lin, R.; Zhang, W.W.; Wu, J.G.; Lin, L.; Du, L.; Liu, W.J. Analysis of physical inactivities and sedentary behaviors of adolescents in Guangzhou. Chin. J. Sch. Health 2012, 33, 788-790.

178. Yang, Z.; Li, M.; Xu, B.H.; Huang, F.; Wang, T.G.; Liu, Y.; Xu, M.; Bi, Y.F.; Xu, Y.P.; Ning, G. Correlation between sedentary time and metabolic syndrome. Chin. J. Pract. Intern. Med. 2011, 31, 883-885.

179. Luo, C.Y.; Wang, P.F.; Luo, X.; Wang, X.D.; Liu, H.Y.; Zhao, Y. Status and Risk Factors of Screen Time among Middle School Students in Shanghai. J. Environ. Occup. Med. 2011, 28, 323-326.

180. He, H.B.; Ni, Y.X.; Zhao, Z.G.; Luo, Z.D.; Zhong, J.; Chen, J.; Yan, Z.C.; Zhu, Z.M. Study on relationship between metabolic syndrome and television-watching time. J. Mod. Med. Health 2011, 27, 3205-3207.

181. Liu, F.D.; Wei, Y.Z.; Yang, X.M. Research on the relationship between Long seating time and seminal fluid parameter changes of IT male sterile patient. Chin. J. Lab. Diagn. 2010, 14, 246-248.

182. Liu, Q.S. Investigation on Public Healthcare Exercises among Sedentary Population in Shanghai. Health Educ. Health Promot. 2009, 4, 38-40.

183. Hong, X.; Yin, X.M.; Liang, Y.Q.; Wang, Z.Y.; Xu, F. Relationship between television watching and obesity: A three-year follow-up study in Nanjing. Chin. J. Public Health 2009, 25, 654-656.

184. Liu, A.L.; Cui, C.H.; Li, Y.P.; Luan, D.C.; Wang, J.Z.; Ma, G.S. Determinants of Television Watching among People in China. Chin. J. Prev. Control Chronic Dis. 2008, 2, 114-116.

185. Hong, X.; Yin, X.M.; Liang, Y.Q.; Wang, Z.Y.; Xu, F. Investigation on Watching Television Time and Type 2 Diabetes Mellitus in Nanjing. Mod. Prev. Med. 2008, 35, 4545-4547+4555.

186. Ma, G.S.; Liu, A.L.; Cui, C.H.; Li, Y.P.; Hu, X.Q.; Luan, D.C.; Yang, X.G. The situation of television viewing of people in China. Chin. J. Health Educ. 2006, 3, 167-170.

187. Ma, G.S.; Li, Y.P.; Hu, X.Q.; Ma, W.J.; Pan, H.; Yang, Y.L.; Ju, J.Y.; Xu, L.C.; Liu, B. The Television Viewing Time of Children and Adolescents Living in Urban China. Chin. J. Health Educ. 2002, 7, 8-10.

188. Hu, Z.M.; Liu, M. Sedentary lifestyle and social factors of permanent residents in Shanghai. Chin. J. Health Educ. 1999, 5, 33-36.

189. Wu, X.Y.; Tao, S.M.; Zhang, S.C.; Zhang, Y.K.; Huang, K.; Tao, F.B. Analysis on risk factors of screen time among Chinese primary and middle school students in 12 provinces. Chin. J. Prev. Med. 2016, 50, 508-513.

190. Wang, N.; Xu, F.; Zheng, L.Q.; Zhang, X.G.; Li, Y.; Sun, G.Z.; Guo, X.F.; Yu, S.S.; Sun, Y.X. Effects of television viewing on body fatness among Chinese children and adolescents. Chin. Med. J. 2012, 125, 1500-1503.

191. Chen, X.R.; Jiang, Y.; Wang, L.M.; Li, Y.C.; Zhang, M.; Hu, N.; Zhao, W.H. Leisure-time physical activity and sedentary behaviors among Chinese adults in 2010. Chin. J. Prev. Med. 2012, 46, 399-403.

192. Zhang, M.; Chen, X.R.; Wang, Z.H.; Wang, L.M.; Jiang, Y. Leisure-time physical exercise and sedentary behavior among Chinese elderly, in 2010. Chin. J. Epidemiol. 2014, 35, 242-245.

193. Guo, H.J.; Ding, C.C.; Yuan, F.; Zhang, Y.; Chen, Z.; Liu, A.L. Sedentary behavior during leisure time and social determinants among Chinese adults in 2010-2012. J. Hyg. Res. 2017, 46, 699-704. 
194. Yang, X.H.; Yu, H.J.; Liu, M.W.; Zhang, J.; Tang, B.W.; Yuan, S.; Gasevic, D.; Paul, K.; Wang, P.G.; He, Q.Q. The impact of a health education intervention on health behaviors and mental health among Chinese college students. J. Am. Coll. Health 2019, 67, 1-6. [CrossRef] [PubMed]

195. Wang, M.; Song, Y.; Baker, J.S.; Fekete, G.; Gu, Y. Sitting to standing postural changes: Energy expenditure and a possible mechanism to alleviate sedentary behavior. Physiol. Int. 2018, 105, 157-165. [CrossRef] [PubMed]

196. Xue, H.M.; Liu, Q.Q.; Tian, G.; Quan, L.M.; Zhao, Y.; Cheng, G. Television Watching and Telomere Length Among Adults in Southwest China. Am. J. Public Health 2017, 107, e1-e8. [CrossRef] [PubMed]

197. Chen, S.; Liu, Y.; Hong, J.; Tang, Y.; Cao, Z.B.; Zhuang, J.; Zhu, Z.; Chen, P. Co-existence of physical activity and sedentary behavior among children and adolescents in Shanghai, China: Do gender and age matter? BMC Public Health 2018, 18, 1287. [CrossRef]

198. Arundell, L.; Fletcher, E.; Salmon, J.; Veitch, J.; Hinkley, T. A systematic review of the prevalence of sedentary behavior during the after-school period among children aged 5-18 years. Int. J. Behav. Nutr. Phys. Act. 2016, 13, 93. [CrossRef]

199. Owen, N.; Healy, G.N.; Matthews, C.E.; Dunstan, D.W. Too much sitting: The population-health science of sedentary behavior. Exerc. Sport Sci. Rev. 2010, 38, 105. [CrossRef]

200. Castro, O.; Bennie, J.; Vergeer, I.; Grégoire, B.; Biddle, S. Correlates of sedentary behaviour in university students: A systematic review. Prev. Med. 2018, 116, 194-202. [CrossRef]

201. Prince, S.; Reed, J.; McFetridge, C.S.; Tremblay, M.; Reid, R. Correlates of sedentary behaviour in adults: A systematic review. Obes. Rev. 2017, 18, 915-935. [CrossRef]

202. Liangruenrom, N.; Craike, M.; Biddle, S.; Suttikasem, K.; Pedisic, Z. Correlates of physical activity and sedentary behaviour in the Thai population: A systematic review. BMC Public Health 2019, 19, 414. [CrossRef]

203. Welk, G. Physical Activity Assessments for Health-Related Research; Human Kinetics: Champaign, IL, USA, 2002.

204. Pedisic, Z.; Bauman, A. Accelerometer-based measures in physical activity surveillance: Current practices and issues. Br. J. Sports Med. 2014, 49, 219-223. [CrossRef] [PubMed]

205. Troiano, R.P.; Gabriel, K.K.P.; Welk, G.J.; Owen, N.; Sternfeld, B. Reported physical activity and sedentary behavior: Why do you ask? J. Phys. Act. Health 2012, 9, S68-S75. [CrossRef] [PubMed]

206. Lee, I.M.; Shiroma, E. Using Accelerometers to Measure Physical Activity in Large-Scale Epidemiologic Studies: Issues and Challenges. Br. J. Sports Med. 2013, 48, 197-201. [CrossRef] [PubMed]

207. Edwardson, C.; Winkler, E.; Bodicoat, D.; Yates, T.; Davies, M.; Dunstan, D.; Healy, G. Considerations when using the activPAL monitor in field-based research with adult populations. J. Sport Health Sci. 2016, 6, 12-178. [CrossRef] [PubMed]

208. Cuesta, A.; Abreu, O.; Alvear, D. Methods for measuring collective behaviour in evacuees. Saf. Sci. 2016, 88, 54-63. [CrossRef]

209. Zhu, W.; Owen, N. Sedentary Behavior and Health: Concepts, Assessments, and Interventions; Human Kinetics: Champaign, IL, USA, 2017; pp. 163-216. ISBN 9781-4504-71282.

210. Ullrich, A.; Voigt, L.; Baumann, S.; Weymar, F.; John, U.; Dörr, M.; Ulbricht, S. A cross-sectional analysis of the associations between leisure-time sedentary behaviors and clustered cardiometabolic risk. BMC Public Health 2018, 18, 327. [CrossRef]

211. Ma, J. The main health problems and countermeasures of Chinese children and adolescents. Chin. J. Sch. Health 2015, 36, 801-804.

212. Schou Andersen, C.; Juhl, M.; Gamborg, M.; Sørensen, T.I.; Nohr, E.A. Maternal recreational exercise during pregnancy in relation to children's BMI at 7 years of age. Int. J. Pediatr. 2012, 2012, 8. [CrossRef]

213. Padmapriya, N.; Shen, L.; Soh, S.E.; Shen, Z.; Kwek, K.; Godfrey, K.M.; Gluckman, P.D.; Chong, Y.S.; Saw, S.M.; Müller-Riemenschneider, F. Physical activity and sedentary behavior patterns before and during pregnancy in a multi-ethnic sample of Asian women in Singapore. Matern. Child Health J. 2015, 19, 2523-2535. [CrossRef]

214. Strong, K.; Mathers, C.; Leeder, S.; Beaglehole, R. Preventing chronic diseases: How many lives can we save? Lancet 2005, 366, 1578-1582. [CrossRef]

215. Koohsari, M.J.; Sugiyama, T.; Sahlqvist, S.; Mavoa, S.; Hadgraft, N.; Owen, N. Neighborhood environmental attributes and adults' sedentary behaviors: Review and research agenda. Prev. Med. 2015, 77, 141-149. [CrossRef]

216. Patterson, R.; McNamara, E.; Tainio, M.; de Sá, T.H.; Smith, A.D.; Sharp, S.J.; Edwards, P.; Woodcock, J.; Brage, S.; Wijndaele, K. Sedentary behaviour and risk of all-cause, cardiovascular and cancer mortality, and incident type 2 diabetes: A systematic review and dose response meta-analysis. Eur. J. Epidemiol. 2018, 33, 811-829. [CrossRef] 
217. Franco, D.; Ferraz, N.; Sousa, T. Sedentary behavior among university students: A systematic review. Revista Brasileira De Cineantropometria E Desempenho Humano. 2019, 21, 1-15.

218. Lee, I.M.; Shiroma, E.J.; Lobelo, F.; Puska, P.; Blair, S.N.; Katzmarzyk, P.T. Effect of physical inactivity on major non-communicable diseases worldwide: An analysis of burden of disease and life expectancy. Lancet 2012, 380, 219-229. [CrossRef]

219. Hallal, P.C.; Andersen, L.B.; Bull, F.C.; Guthold, R.; Haskell, W.; Ekelund, U. Global physical activity levels: Surveillance progress, pitfalls, and prospects. Lancet 2012, 380, 247-257. [CrossRef]

220. Rezende, L.F.M.; Sá, T.H.; Mielke, G.I.; Viscondi, J.Y.K.; Rey-López, J.P.; Garcia, L.M.T. All-cause mortality attributable to sitting time: Analysis of 54 countries worldwide. Am. J. Prev. Med. 2016, 51, 253-263. [CrossRef] [PubMed]

221. Bauman, A.E.; Reis, R.S.; Sallis, J.F.; Wells, J.C.; Loos, R.J.; Martin, B.W. Correlates of physical activity: Why are some people physically active and others not? Lancet 2012, 380, 258-271. [CrossRef]

222. Chen, W.; Zheng, R.; Zeng, H.; Zhang, S.; He, J. Annual report on status of cancer in China, 2011. Chin. J. Cancer Res. 2015, 27, 2-12. [CrossRef] [PubMed]

223. Xu, Y.; Wang, L.; He, J.; Bi, Y.; Li, M.; Wang, T.; Wang, L.; Jiang, Y.; Dai, M.; Lu, J. Prevalence and Control of Diabetes in Chinese Adults. JAMA 2013, 310, 948-959. [CrossRef]

224. Chan, J.C.; Zhang, Y.; Ning, G. Diabetes in China: A societal solution for a personal challenge. Lancet Diabetes Endocrinol. 2014, 2, 969-979. [CrossRef]

225. Hinkley, T.; Teychenne, M.; Downing, K.L.; Ball, K.J.; Hesketh, K.D. Early childhood physical activity, sedentary behaviors and psychosocial well-being: A systematic review. Prev. Med. 2014, 62, 182-192. [CrossRef] [PubMed]

226. LeBlanc, A.G.; Spence, J.C.; Carson, V.; Connor Gorber, S.C.; Janssen, I.; Kho, M.E.; Stearns, J.A.; Timmons, B.W.; Tremblay, M.S. Systematic review of sedentary behaviour and health indicators in the early years (aged 0-4 years). Appl. Physiol. Nutr. Metab. 2012, 37, 753-772. [CrossRef] [PubMed]

227. Tremblay, M.S.; LeBlanc, A.G.; Kho, M.E.; Saunders, T.J.; Larouche, R.; Colley, R.C.; Goldfield, G.; Gorber, S.C. Systematic review of sedentary behaviour and health indicators in school-aged children and youth. Int. J. Behav. Nutr. Phys. Act. 2011, 8, 98. [CrossRef] [PubMed]

228. Hinkley, T.; Salmon, J.; Okely, A.D.; Trost, S.G. Correlates of sedentary behaviours in preschool children: A review. Int. J. Behav. Nutr. Phys. Act. 2010, 7, 66. [CrossRef] [PubMed]

229. Martin, A.; Fitzsimons, C.; Jepson, R.; Saunders, D.H.; van der Ploeg, H.P.; Teixeira, P.J.; Gray, C.M.; Mutrie, N. Interventions with potential to reduce sedentary time in adults: Systematic review and meta-analysis. Br. J. Sports Med. 2015, 49, 1056-1063. [CrossRef] [PubMed]

230. Altenburg, T.; Holthe, J.; Chinapaw, M. Effectiveness of intervention strategies exclusively targeting reductions in children's sedentary time: A systematic review of the literature. Int. J. Behav. Nutr. Phys. Act. 2016, 13, 65. [CrossRef] [PubMed]

231. Owen, N.; Sugiyama, T.; Eakin, E.; Gardiner, P.; Tremblay, M.; Sallis, J. Adults' sedentary behavior: Determinants and interventions. Am. J. Prev. Med. 2011, 41, 189-196. [CrossRef]

232. Springer, A.E.; Kelder, S.H.; Hoelscher, D.M. Social support, physical activity and sedentary behavior among 6th-grade girls: A cross-sectional study. Int. J. Behav. Nutr. Phys. Act. 2006, 3, 8. [CrossRef]

233. Hadgraft, N.; Owen, N. Sedentary Behavior and Health: Broadening the Knowledge Base and Strengthening the Science. Res. Q. Exerc. Sport 2017, 88, 123-129. [CrossRef]

(C) 2020 by the authors. Licensee MDPI, Basel, Switzerland. This article is an open access article distributed under the terms and conditions of the Creative Commons Attribution (CC BY) license (http://creativecommons.org/licenses/by/4.0/). 